\title{
How large immobile sediments in gravel bed rivers impact sediment
} transport and bed morphology

\author{
C. W. McKie ${ }^{1}$, C. Juez ${ }^{2}$, B. D. Plumb ${ }^{3}$, W. K. Annable ${ }^{4}$, and M. J. Franca ${ }^{5}$ \\ ${ }^{1}$ Researcher. University of Waterloo, Department of Civil \& Environmental Engineering, 200 \\ University Avenue West, ON N2L 3G1 Waterloo, Ontario, Canada. Email: \\ chris.w.mckie@gmail.com \\ ${ }^{2}$ Researcher. École Polytechnique Fédérale de Lausanne (EPFL), Route Cantonale, 1015 \\ Lausanne, Switzerland. \& Instituto Pirenaico de Ecología, Consejo Superior de Investigaciones \\ Científicas (IPE-CSIC), Campus de Aula Dei, Avenida Montañana 1005, 50059 Zaragoza, Spain. \\ Email (corresponding author): carmelo.juez@ipe.csic.es \\ ${ }^{3}$ Researcher. University of Waterloo, Department of Civil \& Environmental Engineering, 200 \\ University Avenue West, ON N2L 3G1 Waterloo, Ontario, Canada. Email: \\ ben.d.plumb@gmail.com \\ ${ }^{4}$ Associate Professor. University of Waterloo, Department of Civil \& Environmental Engineering, \\ 200 University Avenue West, ON N2L 3G1 Waterloo, Ontario, Canada. Email: \\ wkannabl@uwaterloo.ca \\ ${ }^{5}$ Professor. IHE-Delft Institute for Water Education, Westvest 7, 2611 AX Delft, The Netherlands \\ \& Delft University of Technology, Department of Hydraulic Engineering, Mekelweg 5, 2628 CD \\ Delft, The Netherlands. Email: m.franca@un-ihe.org.
}

\section{ABSTRACT}

A common approach used to mitigate riverbank erosion and maintain watercourse alignments has been through the application of riprap or larger, more stable particles, to channel boundaries along reaches of interest. Very often, however, these large particles become dislodged from their 
intended locations (failed erosion measures) becoming part of the bed material composition. In natural systems large immobile sediments or boulders can also be found which are often sourced from glacial erratics or colluvial inputs with different spacing and arrangements among them. In lower gradient gravel-bed channels, the impacts that large clasts may impart on river morphologies is uncertain and is studied herein. This paper utilizes laboratory experiments to evaluate the effects that varying spacing of large immobile particles in a gravel-bed channel have on sediment transport and bed morphology. The laboratory experiments consist of a series of test cases with varying spacing of large immobile particles, and one base case with no large immobile particles present. In each case, the flume bed was composed of a poorly sorted gravel mixture with a bi-modal distribution of sand and gravel meant to be representative of a natural gravel-bed channel. The results of the test cases demonstrated that at low spacing of large immobile particles, the transported material and the bed material both became coarser. At medium spacing of large immobile particles, the bed material size and erosion reached a maximum, and the coarser bed material was transported at approximately the same rate as the finer material. Finally, at high spacing of large immobile particles, the size of transported material and bed material sizes were similar to that of the base case, and the sediment transport also had the strongest clockwise hysteresis trend which ultimately led to a net erosion of the gravel-bed channel.

\section{INTRODUCTION}

Large immobile particles can be found in streams naturally, placed as river restoration measures or resulting from failed erosion protection works. When the banks of a stream become unstable in urbanized areas, the resulting erosion can pose a risk to or damage adjacent infrastructure. River management practitioners have traditionally applied hard-engineering approaches to mitigate or remedy such site specific problems. This has included methods such as concrete walls, concrete channel linings, gabion walls or other engineered structures. More recently, softer, more natural approaches are being undertaken to provide a more dynamic and resilient approach to channel stabilization (e.g. Odgaard 2015). These rehabilitation methods range from vegetation plantings on channel banks to vegetated buttress linings (van Dijk et al. 2013). An approach that has been 
commonly used to mitigate erosion or improve bank stabilization issues is the application of riprap or larger, more stable particles to the bank or area of interest. In addition to riprap used for erosion protection, armouring by applying large sediments is often installed at culvert outlets, bridge piers or other stream side locations to protect underlying infrastructure such as watermains, sanitary sewers or pipelines (IOWA Department of Natural Resources 2006).

With riprap and armouring frequently used at varying scales without addressing the fluvial and river mechanic processes that caused the erosive forces within the channel system, such stabilization and protection measures can be insufficient to arrest channel processes and consequently fail (Jafarnejad et al. 2019). Different forms of riprap failure are understood, including particle erosion, transitional slides, and slumping (Blodgett and McConaughy 1986, Jafarnejad et al. 2019). While these failures may be the result of inadequate design or understanding of river system processes, they may also be the result of improper installation (Sutton 2008). These failures are not limited to riprap bank protection but also frequently occur for other types of revetments such as culvert outfalls or bridge piers and abutments (Vermont Department of Environmental Conservation 2013). Regardless of the method of failure, all of these channel responses result in the introduction of large material into the channel bed that may be significantly dissimilar in size relative to the natural bed material grain-size distribution. Some of the methods of introduction, such as bank slumping of a riprap lined bank would introduce the material as a tightly spaced matrix on the channel bed. Alternatively, the erosion of a riprap bank or the failure of material at a culvert outlet might be dispersed loosely on the channel bed. Juxtapose to anthropogenic driven ways of introduction of large particles in stream beds, which is the main motivation of this research, natural streams exhibit many, often similar, large scale immobile sediments or boulders.

The impacts of large particles introduced to channel beds on channel stability, sediment transport and roughness has been studied by various researches with varying outcomes. Brayshaw et al. 1983 proposed that at higher spacing of large particles on channel beds, resistance to flow would increase and sediment transport rates would decrease. Recent studies have found that intermediate spacing of large particles experienced a peak in resistance rather than a large particle spacing being 
proportional to resistance (Hassan and Reid 1990, Yager et al. 2007, Ghilardi et al. 2014a, Ghilardi et al. 2014b, Papanicolaou et al. 2018). There is disagreement in the trends of sediment transport with changes in large particle spacing, with some studies finding that sediment transport follows a decreasing trend with increasing large particle spacing (Ghilardi et al. 2014a, Ghilardi et al. 2014b, Papanicolaou et al. 2018) and others finding the trend to be more complex and not following a consistently increasing or decreasing trend when compared to either resistance to flow or large particle spacing (Hassan and Reid 1990, Church et al. 1998).

Furthermore, many of these former studies used over simplified conditions to gain particular understanding of a complex process such as steady flow (Hassan and Reid 1990, Church et al. 1998, Hassan and Church 2000), uniform sediment (Strom et al. 2004), or no sediment inflow (Hassan and Reid 1990). Moreover, many studies have examined the isolated effects of a single roughness element or a small cluster (Brayshaw et al. 1983, Church et al. 1998, Strom et al. 2004, Tritico and Hotchkiss 2005), which is difficult for assessing channel impacts at larger scale processes. Finally, many of the studies completed to date were based upon a narrow set of experimental conditions, emulating high-gradient river systems typically found in alpine settings (Ghilardi et al. 2014a, Ghilardi et al. 2014b, Aristide Lenzi et al. 2006, Yager et al. 2007, Monsalve and Yager 2017, Monsalve et al. 2017).

Here, we undertook flume experiments, with a moderate channel slope, a bi-modal sand gravel bed composition and variable water and sediment inflow rates to emulate a typical hydrographic flood events within gravel-bed channel morphologies. Data related to sediment transport and bed morphology were collected throughout the experiment. The specific objectives of this research are: i) to provide a holistic interpretation of the effects of large particles on the channel bed and ii) to evaluate the impact that varying spacing of large immobile particles (e.g. rip-rap that has failed from its intended location and is contributing to the bed material) in a gravel-bed channel may have on sediment transport and bed morphology.

\section{EXPERIMENTAL METHODS}




\section{Flume description and measurements}

Laboratory experiments were conducted at the Laboratory of Hydraulic Constructions (LCH) at École Polytechnique Fédérale de Lausanne (EPFL), Switzerland. The flume setup consisted of a $9 \mathrm{~m}$ long by $0.5 \mathrm{~m}$ wide channel (see Figure 1), with a flow stabilization tank and v-notch weir at the upstream end, and a sediment trap at the downstream end. The v-notch weir was verified to be accurate within $+/-10 \%$ based upon a calibrated valve-discharge relationship. Flow parallelisers were included at the upstream end of the flume to remove turbulence created by the v-notch weir and to ensure parallel flow lines entering the flume. A sediment feeder utilizing an Archimedes screw feed introduced a bed material mix at the upstream end, while a valve-adjustable sediment trap collected sediment at the downstream limit of the flume. The adjustable sediment trap outlets to a sediment collection basin, where the sediment was separated from the water and dried prior to analysis.

The flume was equipped with sensors to measure flow depth and bed topography. Water levels were measured all through the experiments by a Baumer ultrasonic probe. The scanning range of these devices is within $2-82 \mathrm{~mm}$ and the resolution below $0.3 \mathrm{~mm}$. We used a sampling frequency of $10 \mathrm{~Hz}$. Differences in the water levels among measuring sections were less than $2 \%$, the uniform flow condition was thus assumed. Furthermore, the flow rate was also monitored by another ultrasonic sensor located in the head tank which was used for discharge calculations relating stage depth to the v-notch weir height.

The bed topography within the study reach was measured by means of an echo-sounder which was operated on a motorized rail system. The vertical accuracy of this device was of $+/-1 \mathrm{~mm}$. Furthermore, a rail and camera mounting platform positioned over top of the flume was employed to capture aerial bed photos using a 12 megapixels mapping camera, which were used to quantify bed material attributes.

\section{Large particle spacing setup}

This experiment was designed to assess how sediment transport and bed morphology may have changed based solely upon changes in the spacing of large immobile particles. All variables 
not pertaining to the spatial spacing of these large particles were kept constant for all test cases, including: input flow hydrograph, sediment input rates, bed and input material distributions, bed slope and large particle sizes and protrusion.

Sediment properties of the channel bed were representative of those lower gradient rivers which can be found in Southern Ontario, Canada (Plumb 2017). Thus, a poorly sorted bimodal sand-gravel mixture with bulk material characteristics for $D_{30 b u l k}, D_{50 b u l k}, D_{84 b u l k}, D_{90 b u l k}$ and $D_{\text {maxbulk }}$ of $0.5 \mathrm{~mm}, 2 \mathrm{~mm}, 6.5 \mathrm{~mm}, 7 \mathrm{~mm}$ and $10 \mathrm{~mm}$, respectively, was used. This material was greater than $10 \mathrm{~cm}$ in thickness, and extended from upstream of the sediment feed to the end of the flume where it transitioned to the sediment trap. The material placed into the sediment feed was same size distribution as the sand-gravel mixture used for the bed.

Based upon the work of Ghilardi et al. 2014a and Ghilardi et al. 2014b, the dimensionless spacing ratio (hereafter referred as spacing) of large immobile particles here was defined by: $\lambda$ / $D$, where $\lambda$ is the distance between centers of particles and $D$ is the median diameter of their distribution. The range in large particle spacing for the experiment was thus based on previous works (Ghilardi et al. 2014a, Ghilardi et al. 2014b), where it was shown that a maximum spacing of $\lambda / D=2$ was dense enough to capture all abrupt changes in sediment transport (varying fractional transport) and bed morphology (aggradation or degradation channel adjustments). As such, this experiment was completed with a range of spacing between approximately $\lambda / D=2$ to $\lambda / D=7$. Additionally a base-case scenario without large particles on the bed was also completed. The test cases and their relevant parameters are listed in Table 1.

Protrusion depths of the large particles were set such that approximately $50 \%$ of each large immobile particle was protruding from the average bed surface. Once all particles were placed on the bed channel surface, the protrusion was set manually to approximately $50 \%$. Visual observation of the protrusion was considered sufficient to guarantee such level of protrusion. Yager et al. 2007 found that the shear stress on the mobile bed sediment is significantly reduced when the protrusion of the immobile particles is relatively large, and low protrusion does not effectively reduce the shear stress on the mobile sediment. Based on the results presented by Yager et al. 2007, a protrusion 
of 50\% presents significant impact to hydraulic variables (flow depth and resulting shear stress) and ultimately, to sediment transport (larger or lower rates of shear stress modulate the resulting sediment mobility). Thereby, a protrusion of $50 \%$ allows to fully visualize the impact of particle spacing to channel dynamics.

\section{Experimental procedure}

Each experiment began with identical initial conditions. Sediment was wetted prior to its addition to the channel bed to avoid vertical sorting of dry sediment during the leveling and moving of the sediment. The material was then graded longitudinally to achieve the same consistent bed slope for the entire flume, and leveled laterally to avoid the formation of lateral bed features during the experiment. A bed slope of $0.01 \mathrm{~m} / \mathrm{m}$ was determined to provide equilibrium sediment transport through the study reach in a base case of no large immobile particles on the bed, which then remained the same for subsequent experiments.

Large immobile particles were introduced onto the channel bed for the remaining experiments in varying arrangements of $\lambda / D$. In order to capture the full effects of the placement of large particles on the bed while minimizing boundary effects, a $2 \mathrm{~m}$ seeded reach was initialized for each experiment within the $3.5 \mathrm{~m}$ study reach (Figure 1). Additionally, only the central $1 \mathrm{~m}$ of this $2 \mathrm{~m}$ reach was used for analysis to avoid impacts of hydraulic transitions into and out of the study reach (Figure 1). It should be noted that during the experiments the water surface within this $1 \mathrm{~m}$ study reach was observed to be at an equivalent slope to the channel bed at all stages of the hydrograph. This was confirmed visually during the experiments and by the analysis of images from a side mounted camera. The large particles were numbered prior to their addition to the flume, and each particle's $\mathrm{a}, \mathrm{b}$ and $\mathrm{c}$ axes were enumerated. These data were gathered for determining the large immobile particles spacing during data analysis, as the average diameter of the placed particles was not exactly the prescribed size of $20 \mathrm{~mm}$ in diameter. The particles were randomly selected and hand placed within the study reach with a distance between each particle corresponding to the current test case. Once all particles were positioned, the particles were pressed into the bed until each particle was approximately $50 \%$ buried. Visual observations of the protrusion were 
considered a sufficient estimate. In reviewing the dataset from Yager et al. 2007 it was found that bed shear stress was not sensitive to small variations in protrusion depths with protrusion depths remained around $50 \%$ of the particle diameter.

Once the bed was prepared, bed photos were taken using a top mounted camera. A series of 12 plan-view photos (each representing $50 \mathrm{~cm}$ of channel length) were taken along the $3 \mathrm{~m}$ stretch of channel containing the study reach, with $10 \mathrm{~cm}$ of overlap with each of the adjacent photos.

After placing the sediment and following similar studies (Waters and Curran 2015, Mao 2012, Plumb 2017), the bed was subsequently slowly saturated and drained to promote initial settlement of the freshly placed sediment. A period of low flow ( 2-3 L/s, below the initial discharge used for the experimental hydrograph), enough to mobilize sand fractions, with no sediment feed was then initialized to provide the channel with a flow history (this process is also known as water-working the channel). These conditions were run for approximately 5 hours and it was considered complete when the sand particles had rearranged such that their mobility was limited in the channel (through visual observation) and there was negligible sediment appearing in the bedload trap. Photos were taken after the completion of the flow history, once the bed had been allowed to drain and dry to avoid reflections caused by standing water and wet particles.

Bed profile scans were conducted immediately before the initiation of each hydrographic event. Scans were completed by backwatering the channel as the echosounder required the bottom of the instrument to be submersed. Backwatering the channel involved closing the bedload trap, running a low discharge through the channel, and raising the downstream gate. Once the water level had reached the bottom of the echosounder, profile data along the entire $3 \mathrm{~m}$ instrumented reach was collected every $1 \mathrm{~cm}$ for the $40 \mathrm{~cm}$ width at the center of the channel. Profiles were not collected within $5 \mathrm{~cm}$ of the channel walls due to the physical limitations of the echosounder. Once the entire bed had been profiled, the channel was drained slowly by turning off the pump and opening the bedload sediment trap.

To commence each experiment, the downstream gate was lowered, the bedload sediment trap valve was opened, and the channel was wetted using a low discharge equivalent to the flow used 
during the flow history. Once the flow had achieved steady-state along the entire channel length, the discharge was increased to the first stage of the hydrograph, the sediment feeder was started, and a collection basket was placed at the bedload trap. Figure 2 illustrates the flow rate, sediment input rate, and bedload collection samples for the hydrograph used in each experimental case. The hydrographs and sediment feed rates were based on the experimental parameters used in Plumb et al. 2019. These rates are scaled to be representative of both the hydrograph characteristics and the bedload transport rates found during the 1-year return period event in a highly urbanized lower gradient gravel-bed river system (Mimico Creek in Toronto, Canada). Since this study compares results obtained during the test cases to that of the base case, and evaluates trends relative to the other data, an exact replication of real-world condition is not required to determine the relative impacts of varying spacing of large immobile particles introduced to the channel bed. It is hypothesized that the adjustment of hydrograph intensity, hydrograph duration and/or sediment supply rates will shift the results found within this paper, however, this will remain a question for further study.

The transported sediment was collected at the sediment trap for the duration of the entire hydrograph, with the collection basket being emptied to start a new sample based on the sample schedule as outlined in Figure 2. This material was later dried, and a grain size distribution for the material was determined.

During each hydrograph, ultrasonic sensors were recording continuously to monitor flow rates. A side-mounted camera and a top-mounted camera obtained photos of the $1 \mathrm{~m}$ study reach at 10 second intervals throughout each experiment. On the opposite side of the flume from the side mounted camera, a $10 \times 1 \mathrm{~cm}^{2}$ grid was installed in order to provide scale for the photos. Upon completion of the hydrograph profile, scans were completed with the echosounder, and bed photos were taken.

A second flow history was conducted at the end of each experiment for a brief period of time (1 hour) in order to allow the sediment to settle and fines to wash away. This procedure was conducted to reproduce field results, in which an extended low flow period would occur after a flow event and before sampling could be completed on the site. After the second flow history, another set of bed 
photos was taken.

\section{Sediment transport ratio and bedload hysteresis}

To compare the sediment transport rates between data from the different test cases, sediment transport ratios and bedload hystereses were compared. The sediment transport ratio (STR) evaluates the balance of sediment through the system, as determined by:

$$
S T R=\frac{Q_{s, \text { out }}}{Q_{s, \text { in }}}
$$

where $Q_{s, \text { in }}[M / T]$ and $Q_{s, \text { out }}[M / T]$ are the sediment transport rates entering and leaving the flume limits, respectively. STR is a measure of the level of sediment storage within the flume, indicating erosive or depositional trends. Bedload hysteresis was calculated by evaluating the hysteresis ratio, which is defined as the ratio of total bedload transport on the rising limb to the total bedload transport on the falling limb (Juez et al. 2018, Plumb et al. 2019). The hysteresis ratio was then plotted against the large particle spacing $(\lambda / D)$ to determine any trends amongst the test cases.

To accompany the analysis of the bedload transport rates, the size of the transported material was also measured and compared between the test cases and the base case. The bedload transport rates and the size of the transported material were compared based on the average values over each hydrograph as well as for the peak discharge states.

\section{Bed surface grain size distribution}

To evaluate the impact of varying spacing of large particles over a hydrograph on the channel bed morphology, the channel surface grain size distribution was compared. To do this, photographs of the channel bed were taken and analyzed for each of the test cases. The post-hydrograph bed material was compared rather than changes over the course of a hydrograph. This was done due to observed variability of initial conditions, with varying amounts of fine material being present on the channel bed after the flow history. Photo analysis was completed using a similar method to that of Mao 2012. The analysis involved taking 5 photos of the channel bed equally spaced along the study reach. The images were scaled using CAD software, and an 8 by 8 grid was superimposed 
over a $0.30 \mathrm{~m} \times 0.30 \mathrm{~m}$ area at the center of each photo (leaving $0.1 \mathrm{~m}$ on each side of the flume to avoid edge effects and overlap between photos). Particles located at each intersection of the grid (Figure 3-left), were measured electronically to determine each particles' b-axis. Once a full set of five photos were analyzed, the b-axis measurements were tabulated into a grain size distribution.

The analysis of each set of photos produced a maximum of 320 measured particles. However, when a grid intersection corresponded to the location of a large, immobile particle, the intersection was skipped to avoid skewing the results based on an increased spacing of large particles. Therefore, the analysis resulted in each photo set containing between 247 and 310 particle measurements.

\section{Particle clustering analysis}

Particle clustering analysis was completed to determine how coarse bed material clustered or dispersed due to the impacts of the large immobile particles. While the bed surface grain size distributions provide an adequate metric for evaluating changes in overall bed surface texture, a more detailed approach was required for the particle clustering analysis to depict the micro-scale changes in bed texture. The software program BASEGRAIN (Detert and Weitbrecht 2013) was utilized to obtain the B-axis measurements for all visible particles in the bed surface photos. Further technical details on the software capabilities can be found in Stähly et al. 2017 . A $50 \mathrm{~cm}$ x $50 \mathrm{~cm}$ area in the center of the study reach was used for the analysis. Due to software constraints and photo resolution, only particles with a b-axis greater than $2 \mathrm{~mm}$ were able to be measured. The b-axis measurements were manually inspected and modified to remove the measurements of the large immobile particles as well as to fix any incorrect measurements provided by the software.

The particle clustering analysis began by associating each particle b-axis measurement produced by BASEGRAIN to the spatial coordinate of the particle center. Observations were turned into a spacing heat map, showing the spatial spacing of coarse bed material, by summing the square of all b-axis measurements within a $1.5 \mathrm{~cm}$ radius of each pixel on the heat map. The b-axis measurements were squared prior to the summation to provide more weight to coarser particles. The areas overlapping the large immobile particles were removed from the analysis.

To observe the particle clustering changes due to the hydrograph applied, processed images or 
heat maps before and after each hydrograph step were compared. The result was a heat map where positive values indicated areas where more coarse material clustered over the hydrograph, and negative values indicating the opposite trend. An example of this resultant heat map, in addition to the heat maps of before and after the hydrograph, are shown in Figure 3-right.

Using the final heat map, the following three metrics for comparing the particle clustering data were used to compare the experiments: (i) mean ratio: ratio of the average positive pixel values to the average negative pixel values, to distinguish whether increases or decreases prevalent for a given experiment; (ii) increasing/decreasing area ratio: the ratio of positive pixels to negative pixels, to identify spatially the proportion of study bed area that experienced increased clustering of the bed area relative to areas that experienced decreased clustering; and (iii) sum ratio: the ratio of the sum of all positive pixels to the sum of all negative pixels, to identify whether the overall bed trends were increased or decreased particle clustering.

\section{Fractional transport analysis}

Fractional transport analysis was used to evaluate the relative mobility of the different particle size classes within the bedload samples (Parker et al. 1983, Wilcock and Southard 1988, Church and Hassan 2002). Following the methods presented by Wilcock and Southard 1988 and Church and Hassan 2002, the fractional transport ratio $\left(P_{i} / f_{i}\right)$ was defined as the ratio between a size fraction $i$ 's proportion in the bedload material $\left(P_{i}\right)$ and its proportion in the bulk bed material $\left(f_{i}\right)$. The fractional transport ratio was then scaled by the unit bedload discharge $\left(q_{b i}\right)$ of size fraction $i$ to obtain the scaled fractional transport ratio $\left(q_{b i} P_{i} / f_{i}\right)$. Bulk material characteristics were used here for reasons consistent with Church and Hassan 2002 who found that the bulk material was more representative of the reference material for fractional transport analysis. They found that this observation was attributed to the uncertainty in the surface material composition at the time of transport, as well as the lack of fines within the surface material that is prevalent in the bedload material.

Scaled fractional transport was evaluated by using the dimensionless unit bedload flux $\left(q_{b i}^{*}\right)$, which is a method presented by Parker et al. 1983. The dimensionless unit bedload flux was thus 
defined as:

$$
q_{b i}^{*}=\frac{q_{b i} f_{i}^{-1}}{\sqrt{\left[\left(\rho_{s} / \rho_{w}\right)-1\right] g D_{g i}} D_{g i}}
$$

where $q_{b i}\left[\frac{M}{L \cdot T}\right]$ is the unit bedload transport rate of the given grain size fraction of interest, $f_{i}$ is the fraction of the size class in the bed surface material, $\rho_{s}$ is the sediment density $\left(2650 \mathrm{~kg} / \mathrm{m}^{3}\right)$, $\rho_{w}$ is the water density $\left(1000 \mathrm{~kg} / \mathrm{m}^{3}\right)$, and $D_{g i}[L]$ is the geometric mean of the sediment size class diameter. This method is compared against the modified Meyer-Peter and Müller equation (Wong and Parker 2006):

$$
q^{*}=4.93\left(\tau_{b}^{*}-0.0470\right)^{1.6} \quad \text { with } \quad \tau_{b}^{*}=\frac{\tau}{g\left(\rho_{s}-\rho_{w}\right) g D_{50}}
$$

The shear stress was determined at each flow step from the measured flow depth observations using the ultrasonic sensors and the bed slope with the following equation (Julien 2002):

$$
\tau=\gamma R_{h} S_{0}
$$

where $\gamma$ is the specific weight of water $\left(9800 \mathrm{~N} / \mathrm{m}^{3}\right), R_{h}$ is the hydraulic radius, and $S_{0}$ is the flume bed slope $(0.01 \mathrm{~m} / \mathrm{m})$.

Equation 3 determines which size classes are either being over represented or under represented in the bedload composition when compared to the sediment in the bed material. Results are compared across all test cases, the base case and Equation 3. By determining the representation of the size classes, inferences can be made about the hiding of material by the large immobile particles, and the effects that large immobile particles may have on the applicability of typical sediment transport equations.

\section{Profile scan data}

41 longitudinal profiles were collected normal to the principal flow direction across the flume width both before and after each hydrograph. These profiles were averaged to create one composite 
profile for the entire flume width over the $1 \mathrm{~m}$ study reach. The profiles were averaged rather than compared discreetly since the analysis was completed to gain an overall understanding of whether there were elevation or slope changes from the influences of the large particles introduced to the channel bed. The profiles were thus evaluated for the average change in channel elevation as well as the final bed slope for each of the five test cases and the base case.

\section{RESULTS}

\section{Bedload transport data}

The sediment transport rates for each hydrograph step were measured during each experiment. The sediment transport ratio (STR) of each case shows that increasing the spacing between the large immobile particles results in an increase in the sediment transport rate except between $\lambda / D=1.92$ to $\lambda / D=2.63$, where there is a decrease. Figure 4 shows the sediment transport ratios for the bulk sample, but also for the fine and coarse fractions of the bed material (separated by a particle diameter of $2 \mathrm{~mm}$ ). There is notable increase in the sediment transport rate from a large particle spacing of $\lambda / D=2.63$ to $\lambda / D=3.82$ for both the peak discharge (Figure 4B) and the entirety of each hydrograph (Figure 4A). The observed increase is a result of increased fine material transport (evidenced by a decreasing STR in the coarse fraction), as $\lambda / D$ decreases over this range. Interestingly, the coarse sediment transport ratio is lower for Test Case $5(\lambda / D=6.75)$ than it is for Test Case $4(\lambda / D=5.17)$ at the peak discharge.

The sediment transport ratios of the base case were 2.80 and 6.62 for the entire hydrograph and the peak discharge, respectively, which are higher than any of the test cases. It should be noted that for the entire hydrograph, the sediment transport ratio was less than one for the highest spacing cases (Test Cases 1 and 2), indicating that there was more sediment stored than eroded in the system during each hydrograph. This is further in connection with a reduction of bed elevation as it is explained below in Figure 7.

Figure 4 also shows that the fine fractions have a greater sediment transport ratio than the coarse fractions for the highest spacing cases for both the entire hydrograph and at the peak flow. As the spacing of large particles decreases, the coarse sediment trends to a higher ratio than the 
fine sediment. For the entire hydrograph, the STR of the coarse and fine material nearly reaches equivalency during Test Case 4; meaning that the fine and coarse material are similarly eroded out or deposited within the flume bed. When examining the peak discharge only, nearly equity is achieved between $\lambda / D=1.92$ and $\lambda / D=2.63$.

The results presented in Figure 4 confirm than an adequate range in large immobile particle spacing was tested. Ghilardi et al. 2014a and Ghilardi et al. 2014b noted that large particle spacing between $\lambda / D=2$ and 3 capture the significant drop in sediment transport within this range. The results presented in Figure 4 show that this study was able to capture this significant drop which appears between Test Case 2 and 3.

Figure 5 shows the change in transported sediment size relative to the base case, for both the cumulative data over the entire hydrograph (Figure 5A) and for the isolated peak discharge (Figure 5B). For reference, during the entire hydrograph the base case transported material sizes of 0.32 $\mathrm{mm}, 0.45 \mathrm{~mm}, 1.3 \mathrm{~mm}, 4.4 \mathrm{~mm}$ and $5.3 \mathrm{~mm}$ for the $D_{16}, D_{25}, D_{50}, D_{75}$ and $D_{84}$ respectively. Additionally, during the peak discharge the transported sediment sizes during the base case were $0.37 \mathrm{~mm}, 0.53 \mathrm{~mm}, 1.78 \mathrm{~mm}, 4.82 \mathrm{~mm}$ and $5.84 \mathrm{~mm}$ for the $D_{16}, D_{25}, D_{50}, D_{75}$ and $D_{84}$ respectively.

The overall observed trends identify that an increase in large particles spacing causes an increase in the transported material size until the highest tested spacing, as shown by values of $<0 \%$. As $\lambda / D$ decreases (large particle spacing increases), transported material sizes become smaller. For both the cumulative hydrograph and for the isolated peak discharge observations, the highest spacing cases (Test Cases 1 and 2) relate to a decrease in particle size of all fractions. At the highest spacing case, all particle size fractions are smaller than the base case for both the entire hydrograph and at the peak discharge. However, for all cases apart from the highest spacing case, particle size generally increases when compared to the base case. The increase in particle size from a large particle spacing of $\lambda / D=1.92$ and $\lambda / D=2.63$ is a much larger increase than the other observed transported particle sizes found at lower large particle spacing. Figure 5 shows the impact of large particle spacing on the transported particle grain sizes based upon the median particle size $\left(D_{50}\right)$ 
transported. Additionally, the fine fractions are more impacted by the large particle spacing than the coarse fractions.

\section{Bed material size}

Figure 6 depicts the difference in bed material size found after each hydrograph test case relative to the base case. The highest spacing case (Test Case 1) yields results nearly equivalent to that of the base case, with the bed material increasing as the spacing of the large particles decreases. For reference, the base case bed material after the hydrograph had a $D_{30}, D_{50}, D_{60}, D_{84}$ and $D_{90}$ of $2.5 \mathrm{~mm}, 3.3 \mathrm{~mm}, 3.9 \mathrm{~mm}, 6.2 \mathrm{~mm}$ and $7.1 \mathrm{~mm}$ respectively.

Figure 6 further illustrates that the percentage change in selected grain size $\left(D_{i}\right)$ is less than for the coarser percentiles for nearly all of the test cases; except for Test Case 1 where all percentiles were approaching the same sizes found during the base case. Additionally, the $D_{60}$ and $D_{84}$ grain sizes of the bed material are both larger during all test cases than the corresponding size classes during the base case, whereas the $D_{30}$ and $D_{50}$ experience decreases in particle size during the highest spacing test case. The results show that the coarsest particle size fraction is less impacted by changes in large particle spacing than the other size classes. There does appear to be a maximum in the bed material size during Test Case 4. This maximum is shown in the $D_{30}, D_{50}$ and $D_{60}$, but the $D_{84}$ and $D_{90}$ experience a maximum at the lowest large particle spacing.

\section{Erosion and Slope Change}

Using the composite profile data from each experiment, erosional and depositional trends of the channel bed and changes in slope within the study reach were able to be determined. Figure 7 presents the results of this analysis. Changes in both elevation and slope (Figure 7) are less at the lower spacing cases (Test Cases 3,4 and 5) than the differences found in the higher spacing cases (Test Cases 1 and 2). Bed elevations increased by 35\% and 39\% relative to the base case for Test Case 1 and Test Case 2, respectively, compared to 133\%, 98\%, and 78\% for the remaining test cases. Correspondingly, the final bed slopes for Test Case 1 and Test Case 2 were $61 \%$ and $41 \%$ steeper than the base case, respectively, whereas the other 3 test cases are ranged between $7 \%$ and $17 \%$ steeper. These results reveal that the higher spacing cases experienced less bed erosion and a 
greater increase in bed slope within the study reach than the lower spacing cases.

The impact of the large immobile particles on the channel slope thus causes an increase of the bed slope until the spacing of the large particles reaches $\lambda / D=3.82$, after which lower spacing of large particles show little difference in slope from the base case. The change in channel bed elevation over each hydrograph is reduced for Test Cases 1 and $2(\lambda / D=1.92$ and $\lambda / D=2.63$ respectively), a small increase for Test Case $3(\lambda / D=3.82)$, approximately equal change as the base case for Test Case $4(\lambda / D=5.17)$, and a lesser reduction for Test Case $5(\lambda / D=6.75)$.

\section{Particle Clustering Analysis}

Results of the particle spacing analysis show that there is an increase in coarse particle clustering as the spacing of the large immobile particles decreases. Figure 8 depicts this particle clustering trend using different metrics: the sum ratio, the increasing/decreasing area ratio and the mean ratio.

An increasing trend in coarse material spacing is consistent through all of the test cases except for Test Case 4, which is below both Test Case 3 and Test Case 5 cases. If either Test Case 3 or Test Case 4 were removed, the trend of increasing coarse material clustering while large particle spacing decreases would hold, with the deviation likely being due to experimental variability. The base case shows a slight decrease in coarse particle clustering, which is opposite to the results of all of the test cases.

\section{Bedload hysteresis}

The bedload hysteresis analysis focused on the differences in sediment transport rates between the rising and falling limbs of each hydrograph. The phase plot of sediment transport rates versus discharge resulted, in general, in clockwise loop trends (greater transport during the rising limb of the hydrograph) for the base case and for nearly all of the test cases; Test Case 3 as shown in Figure 9 is representative of the majority of experiments. Findings here are consistent with those of Mao 2012 where clockwise hysteresis loops were found for every hydrograph of a laboratory experiment. Interestingly, the current results of Mao 2012 are opposite to those of Waters and Curran 2015, where a counterclockwise hysteresis was found on the first hydrograph of their lab experiments. A study by Juez et al. 2018, who conducted suspended sediment flume-based experiments, showed 
that the nature of sediment hysteresis may be a result of the distance between the origin of the sediments and the observation position. In our experimental campaign, for Test Cases 1-3 and 5, the hysteresis is dominated by a clockwise trend and according to Williams 1989 this may indicate that an armored layer forms making sediment less available on the falling limb. Conversely, Test Case 4 shows a figure eight trend, with a clockwise trend dominating the higher flows in the hydrograph. A figure eight trend could be an indication of an armour layer breakup on the falling limb (Williams 1989).

The base case exhibits a sediment transport ratio of greater than 1 for the first step of the rising limb (Figure 9), whereas the remaining test cases do not (with the exception of Test Case 5). The general observed trend was that the sediment transport characteristics of Test Cases 1 through 5 approached that of the base case with decreasing large immobile particle spacing. Additionally, for all but one of the test cases and the base case, the maximum STR occurs during the peak discharge. The differences in STR between the peak discharges and steps before each peak discharge become smaller as the spacing of the large immobile particles increased. Accordingly, during the highest immobile particle spacing case (Test Case 1), the STR of the discharge step before the peak discharge exceeded that of the peak.

The hysteresis characteristics of each experiment are summarized in Figure 10, which shows the results as a hysteresis ratio. This hysteresis parameter is calculated as the ratio of the rising limb output yield to the falling limb output yield. With the exception of the figure eight trend observed in Test Case 4, the hysteresis ratios have clear decreasing trends with decreasing large immobile particle spacing (Plumb 2017, Juez et al. 2018). Additionally, all test cases have a higher hysteresis ratio than the base case. Test Case 4 exhibits an outlying figure-eight hysteresis trend which does not follow the decreasing trend as shown in the other test cases. The highest spacing case has a hysteresis ratio $50 \%$ greater than the base case, with all cases (excluding Test Case 4) being substantially greater than the base case. It is notable that all cases, including the base case, have a hysteresis ratio greater than 1.5. This finding indicates that the sediment transport on the rising limb of each hydrograph is much greater than that of the falling limbs. 
As Figure 10 shows, Test Case $4(\lambda / D=5.17)$ is lower than would be expected based upon the results of the other 4 test cases. A possible explanation is that the armour layer broke up during the test case, which would lead to an increased sediment transport rate on the falling limb as the armour layer began to redevelop. This assertion is supported by: Figure 8 which shows less coarse material clustering over the Test Case 4hydrograph; Figure 7 which shows that Test Case 4 experienced the greatest amount of erosion of all the test cases; and, Figure 4 which depicts that Test Case 4 had the highest sediment transport rates of all of the test cases.

\section{Fractional transport analysis and dimensionless bedload rating curve}

The dimensionless unit bedload flux $\left(q_{b i}^{*}\right)$ was calculated for each step of the hydrograph for all test cases and the base case. These data were then compiled into dimensionless bedload rating curves by comparing the bedload flux to the dimensionless shear stress by employing Equations 2-4, with results shown in Figure 11. The dimensionless bedload rating curves were plotted against the rating curves generated by applying the modified form of the Meyer-Peter and Muller bedload transport equation (Wong and Parker 2006). Transport rates were observed to be lower for increases in large immobile particle spacing for most particle sizes in transport (ie. particle sizes of 1.41-2 $\mathrm{mm}$ and 2-2.8 $\mathrm{mm}$ compared between Test Cases 1 and 5). The exceptions appear to be the largest (particle size between 8 to $11.3 \mathrm{~mm}$ ) and smallest transported particle sizes (particle size less than $0.125 \mathrm{~mm}$ ) which appear to be unaffected by changes in large immobile particle spacing. The rest of the spacing configurations did not have an effect on the transport of the individual grain sizes. Furthermore, in all cases, the modified Meyer-Peter and Müller bedload transport formula over predicted the transport of fine-grain material fractions (right-side of the diagram) and under predicted the transport of coarse material fractions (left-side of the diagram). These observed deviations are due to the lack of hiding and exposure correction algorithms (see Egiazaroff 1965, Parker 1990, Wilcock and Crowe 2003, Wu et al. 2000) to account for a wide range of sizes in the modified Meyer-Peter and Müller bedload transport formula. The dimensionless bedload flux for the median particle sizes (from $1 \mathrm{~mm}$ to $2.8 \mathrm{~mm}$ ) was noted to be lower than those for slightly coarser or finer material. 
A fractional transport analysis for each test case and the base case determined both the fractional transport ratios and the scaled fractional transport rates with results shown in Figures 12 and 13 respectively. Figure 12 shows that the coarse material fractions are less represented in the bedload in the final discharge steps of the falling limbs. This is shown by the fractional transport ratios for the $7.875 \mathrm{~L} / \mathrm{s}$ (Falling) time-step being lower for the coarse material (approximately greater than $2 \mathrm{~mm}$ ) and higher for some of the fine material fractions (between approximately 0.3 and 1 $\mathrm{mm}$ ) when compared to other time-steps. Variability in the fractional transport ratios is less for the finer material, and greater for the coarser material as the large immobile particle spacing increases indicating a trend in the partial transport (Ashworth and Ferguson 1989, Wilcock and McArdell 1997). Excluding the first and last stages of each hydrograph, lower spacing of large particles correspond to conditions close to unity in the fractional transport ratios across all size classes. In cases where higher large immobile particle spacing were tested, the size selectivity towards the fine to medium particle sizes increases as shown through the higher peak in the fractional transport ratio between 0.2 and $1 \mathrm{~mm}$ sediment sizes during higher spacing cases (see Figure 12). Further, finer grain-size classes are mobilized more during the rising limbs of each experiment and have values closer to unity, with much lower fractional transport ratios for the fine material during the falling limbs.

Based upon the scaled fractional transport rates (Figure 13), the changes in scaled fractional transport at the coarser sediment sizes (greater than $1 \mathrm{~mm}$ ) is greater than the changes seen in the finer fractions. All of the test cases and the base case show a decrease in scaled fractional transport rates about the median particle size of $2 \mathrm{~mm}$. Scaled fractional transport rates for the falling limbs decreased in greater proportions, relative to the rising limbs, as the sediment size increased. This effect is more easily observed in the higher spacing cases, but is present in all cases (Figure 13). The variability of the finest particle size in terms of the scaled fractional transport rate is the greatest for the base case, with the variability decreasing as the large particle spacing increases. Finally, the peak discharge displays a notable drop in the fractional transport rate for the range of sediment size from $2 \mathrm{~mm}$ to $8 \mathrm{~mm}$ as the large particle spacing increases, with a reduction being observed in 
nearly all sediment sizes, but not as visually evident.

\section{DISCUSSION}

\section{Holistic interpretation of the results}

A common interpretation of gravel-bed systems with large particles protruding from the channel bed is that there is a general drop in shear stress on the channel bed resulting in a reduced sediment transport capacity (Ghilardi et al. 2014a, Ghilardi et al. 2014b, Brayshaw et al. 1983, Hassan and Reid 1990, Yager et al. 2007, Nitsche et al. 2011, Yager et al. 2012). The synopsis being that the average force being exerted on mobile bed sediments is reduced as the spacing of large immobile particles increases. However, the results within this study do not fully agree with this anticipated trend of an overall drop in bed shear stress. This is shown through changes in sediment transport and bed morphology.

Initially, it was anticipated that the introduction of large immobile particles would cause decreased shear stress and that the expected size of the transported material during the base case would always be coarser than material being transported during cases with large immobile particles present. While the observed sediment transport rates decreased as the spacing of the large immobile particles increased as predicted (Ghilardi et al. 2014a, Ghilardi et al. 2014b, Brayshaw et al. 1983, Hassan and Reid 1990, Yager et al. 2007, Papanicolaou et al. 2018), in the current experiments, the size of the transported material was not found to consistently decrease as higher spacing of immobile particles were introduced. Instead, the size of the transported material at the highest spacing cases (Test Case 1 and 2) was very similar to that of the case where no large particles were present. Conversely, lower spacing of large immobile particles corresponds with an increase in the transported particle size. This trend is evident in Figures 4 and 5 where the fraction of coarse material being transported decreases as the spacing of large immobile particles increases.

The bed texture findings here also do not follow the expected trends (Figure 6) where the large immobile particles would be expected to cause an increase in bed roughness and a decrease in shear stress acting on mobile sediments, and thus, finer material would be maintained on the channel bed as it would not be able to be entrained (Ghilardi et al. 2014a, Yager et al. 2007). However, 
the results of this study show that the channel bed is immediately coarser by 20 to $30 \%$ at the highest immobile particle spacing case, then results show an increase in bed material size as the large immobile particle spacing increases to $\lambda / D=5.17$ (Test Case 4 ), followed by a decrease in particle size until the maximum tested spacing of $\lambda / D=1.92$ (Test Case 1) which had bed material consistent in size with the base case. It should be noted that the increase in bed material size from Test Case 1 to Test Case 2 was the greatest increase in particle size between test cases, indicating that this may be related to the spacing in which flow structures are being impacted the most. Therefore, a drop in shear stress does not adequately provide an explanation for the processes causing an increase in bed material size due to the presence of large immobile particles.

The sediment transport (Figure 5) and bed texture (Figure 6) data support a more complex explanation on reduced shear stress and increased resistance to flow, that can be developed from existing literature (Brayshaw et al. 1983, Tan and Curran 2012, Hassan and Reid 1990). Brayshaw et al. 1983 found that isolated large particles on a channel bed created localized areas of increased total kinetic energy and turbulence in the horizontal plane on the lee side (downstream side) of the particles. If unaffected by downstream obstructions, this would result in increased shear stress and scour holes on the downstream side of the particles (often associated with imbrication). These isolated obstructions also provide areas that are protected from high energy flows where material could deposit. Hassan and Reid 1990 identified that at high spacing of large particles, the flow skimmed over the tightly spaced particles. This high energy skimming flow created powerful eddies that acted on the channel bed in the larger gaps of the randomly placed particles. Tan and Curran 2012 further identified that when particle clusters were at a specific spacing, the flow patterns of the clusters amplified each other, resulting in an increase in the power of the turbulence structure between them. When the clusters were spaced further apart, the flow patterns began to resemble isolated clusters. Alternatively, spacing the clusters closer together resulted in the flow patterns interfering with each other and reducing the energy of the turbulence cells. Yager and Schmeeckle 2013 show that local sources of roughness may increase sediment transport.

A more integrated explanation of the trends in sediment transport and bed morphology due to 
the effects of introduced large immobile particles is thus made up of three key mechanisms: (i) isolated large immobile particles create localized areas of increased erosive forces, and localized protected areas (Brayshaw et al. 1983, Monsalve and Yager 2017, Monsalve et al. 2017); (ii) at a narrow range of large immobile particle spacings, flow structures build upon each other and amplify their erosive forces (Tan and Curran 2012); and (iii) densely spaced large immobile particles cause high energy skimming flow that is able to create powerful eddies in gaps between the large particles (Hassan and Reid 1990). This framework is used to explain the trends observed in the current study for the observed sediment transport rates, size of transported materials, and bed textures.

During the low spacing cases, coarser material was transported when compared to the base case and the bed surface was coarser. This is explained through the study presented by Brayshaw et al. 1983. Low spacing of large immobile particles provided isolated areas of increased energy that allowed for the mobilization of material that could not be mobilized during the base case, which caused the increase in transported material size. The scour holes created in this process would contain the coarse material that the increased energy could not mobilize, resulting in an increased bed material size.

As the large immobile particle increases, the sediment transport rate peaks then decreases, the size of transported material decreases and the bed material size peaks then decreases. The peaks in sediment transport rates are indicative of the large immobile particle spacing passing the point in which the flow structures build upon each other and create more erosive force, mobilizing more material and creating larger scour pools armoured with coarse material (Tan and Curran 2012). The drop in the grain-size of the transported material is likely the result of the coarse material that is mobilized in the scour pools being deposited in an increasing number of areas where the large immobile particles shield the bed from the the highest bed shear and near-bed velocities (Brayshaw et al. 1983).

At the highest immobile particle spacing, the size of the transported material and the bed material size is nearly equivalent to that found in the base case. This can be attributed to a condition where these metrics reach a balance when the flow is of the skimming type (Hassan and Reid 1990). 
The bed areas experiencing skimming flow are well protected from the high energy flow which would allow fine material to deposit in the tight spaces between the large particles. These processes also contributes to the drop in sediment transport rates. In the areas where there is a bigger gap between the large particles and the high energy flow is able to impinge on the channel bed, scour holes are formed exposing coarse material. While a greater proportion of coarse material is likely able to be mobilized than during the base case as a result of this high energy flow, this coarse material would likely be deposited prior to reaching the sediment trap. For the size of transported material, a balance is reached between coarse material that is mobilized from the scour holes and the coarse material that is deposited in lower energy areas, resulting in similar results to the base case. Similarly, the bed material is a balance between the coarse material present in the scour holes and the fine material trapped between the densely spaced particles, which results in a similar surface texture to the base case. It is predicted, that if the spacing of large particles increases, the areas in which the eddies could impinge would reduce or disappear, resulting in a fining of both the transported material and the bed material in relation to the base case.

It is noteworthy that the spacing of large immobile particles on the channel bed had less impact on the finest and coarsest size fractions of the transported material than the impacts on the interquartile size fractions, as shown by Figure 5. While the limited change in the extreme fine and coarse fractions could be attributed to sediment availability (i.e. once the fines have been washed off the bed surface, other material will need to be eroded for more fine material to become available), the fractional transport analysis as shown in Figure 12 depict that availability is not the cause of this due to their under-representation in the transported sediment. When comparing the fractional transport at the higher discharges of $14.5 \mathrm{~L} / \mathrm{s}$ and $16 \mathrm{~L} / \mathrm{s}$ on the rising limb and $14.25 \mathrm{~L} / \mathrm{s}$ on the falling limb, the material around 2-3 mm exhibits the greatest changes between the different test cases. In contrast, the fine and coarse material fractions stay relatively constant between all cases. During the base case, it is likely that as the finer material is eroded, the channel bed becomes armoured. The inclusion of the large particles and their resultant eddies will produce an increased transport capacity in localized areas and will provide for the ability to mobilize some of this coarser 
armour material. It has been previously identified that material on the downstream side of an obstruction or particle cluster is more frequently mobilized, and once mobilized, this material has shorter travel distances (Brayshaw et al. 1983). This could cause the coarse material that forms the armour layer to be mobilized due to the powerful eddies acting on the bed, allowing more easily transported material to be conveyed, with the coarse material being deposited in lower energy areas shortly downstream. With the deposition of this coarser material, it allows for the increased storage of fine materials in the interstitial spaces created. Despite the coarse material being mobilized, the low transport distances is a possible explanation for the lack of representation due to the material inability to reach the bedload trap in the flume.

\section{Bed surface texture}

Larger spacing of particles increases hydraulic resistance and, consequently, flow velocity is lower and sediment erosion is minimized (see change elevation results for $\lambda / D=1.92,2.63$ in Figure 7). Thus, it is expected that large particles remain in place or migrate more slowly, "locked" by the neighboring large particles and lower hydraulic forces exerted over the bed channel. On the contrary, lower spacing of particles introduce localized scour pockets, exposing larger bed surface areas and enhancing surface turbulence (Tan and Curran 2012). As a result, the large particles become unlocked and migrate following the streamlines. This results in particles clustering which, ultimately, leads to the formation of larger scour and more complex turbulent eddies increasing sediment export from the channel reach (see change elevation results for $\lambda / D>3.80$ in Figure 7).

\section{Bedload Hysteresis}

The bedload hysteresis is generally increasing with large particle spacing (with positive values being in reference to clockwise hysteresis, or more sediment transport on the rising limb than the falling limb). Test Case 4 was an exception to this, experiencing a figure 8 loop. As discussed previously, this could be the result of an armour layer breakup, resulting in increased sediment transport rates during the falling limb (Orrú et al. 2016). This supports the proposed concept that large particles on the channel bed create more powerful eddying effects in the small scour holes on the downstream side of the particles (Hassan and Reid 1990, Dermisis and Papanicolau 2014). 
During the rising limb, since it is the first time the channel bed has experienced flows above a low flow, material is being eroded from the scour holes. On the falling limb, these scour holes begin to fill with material as the scouring force is decreased to a point where material can deposit and the transport capacity in these areas is decreased.

\section{Channel Profile}

The overall erosion trend observed is likely a result of the bed material experiencing flows of the tested magnitudes for the first time during the hydrograph, causing the washout of unsettled and unstable material prior to an armour layer forming (Plumb 2017). The lower level of erosion present at the highest spacing is in line with other studies that suggest that large particle spacing is proportional to the overall bed resistance (Hassan and Reid 1990, Tan and Curran 2012, Dermisis and Papanicolau 2014). An interesting result is that the erosion does not increase with a decrease in large particle spacing throughout the range of tested spacing as expected. Instead, from a spacing of $\lambda / D=3.82$ to $\lambda / D=6.75$, the bed experiences a decreasing amount of erosion. This is unexpected as the anticipated relationship between large particle spacing and resistance would suggest that as large particle spacing decreases, the erosion amount would increase, approaching a maximum value at the base case. A possible explanation for this may be that at a spacing between $\lambda / D=2.63$ and $\lambda / D=5.17$, there is a point where the large particle spacing corresponds to the ideal spacing required for flow structures to build upon each other (Tan and Curran 2012). This spacing would represent the case with the greatest number of well developed scour holes and the least amount of interfering flow patterns, leading to the greatest amount of erosive force.

\section{CONCLUSIONS}

This study investigated the effects of varying spatial spacing of large immobile particles on sediment transport and bed morphology of a gravel-bed channel. A laboratory experiment was conducted to study this relationship by simulating a hydrograph over an alluvial bed in a flume. This research was aimed to present a more detailed look at the effects of large immobile particles on a channel bed, and to provide a more holistic overview to consolidate the findings of previous studies. 
The results showed that the test cases corresponding to low spacing of large immobile particles experienced a decrease in sediment transport rate, but an increase in the size of the transported material when compared to the base case. The bed in these cases experienced an increase in bed material size and an increase in coarse material clustering. These cases also experienced a more distinct clockwise hysteresis pattern with the coarse material comprising a greater fraction of the transported material.

As the experiments transitioned to the intermediate spacing of large immobile particles, the sediment transport rates further decreased, and the size of the transported material also began to decrease. The channel bed experienced the greatest increase in bed material size during these cases, as well as experiencing the greatest amount of erosion. The hysteresis of these intermediate cases was an even stronger clockwise trend, while the sediment transport approached equal mobility.

Finally, at the highest spacing of large immobile particles the size of transported material, the bed material size and the amount of coarse material clustering were all similar to the results presented in the base case. Despite these similarities, the bed experienced an increase in slope and decreased erosion compared to the base case. Additionally, the highest spacing cases experienced the strongest clockwise hysteresis trends and the greatest bias towards size selective transport.

The results presented within this study demonstrate that the effects of large immobile particles cannot be explained simply by relating large immobile particles spacing to an increase in channel roughness and a decrease in transport capacity. The major outcomes of our research are summarized in three points: (i) isolated large immobile particles create localized areas of increased erosive forces, and localized protected areas (Brayshaw et al. 1983); (ii) at a narrow range of large immobile particle spacings, flow structures build upon each other and amplify their erosive forces (Tan and Curran 2012); and (iii) densely spaced large immobile particles causes high energy skimming flow that is able to create powerful eddies in gaps between the large particles (Hassan and Reid 1990).

\section{DATA AVAILABILITY STATEMENT}

Some or all data, models, or code generated or used during the study are available from the corresponding author by request (experimental data). 


\section{ACKNOWLEDGMENTS}

Thanks are owed to the two reviewers, the Associate Editor, and the Editor, whose insightful, thoughtful and helpful comments greatly improved the quality of the final paper. Special thanks are extended to Prof. Anton J. Schleiss for providing laboratory resources to conduct these experiments. This project was supported by funding from an NSERC IPS (McKie), by the H2020-MSCA-IF-2018 programme (Marie Sklodowska-Curie Actions) of the European Union under REA grant agreement number 834329-SEDILAND (Juez) and by Water Regime Investigations and Simulations Ltd., JTB Environmental Systems Inc. and R\&M Construction (Plumb). Data from these experiments are available from the corresponding author upon request. 


\section{REFERENCES}

Aristide Lenzi, M., Mao, L., and Comiti, F. (2006). "When does bedload transport begin in steep boulder-bed streams?.” Hydrological Processes, 20(16), 3517-3533.

Ashworth, P. J. and Ferguson, R. I. (1989). "Size selective entrainment of bed load in gravel bed streams." Water Resources Research, 25(4), 627-634.

Blodgett, J. and McConaughy, C. (1986). "Rock riprap design for protection of stream channel near highway structures, Volume 2 - Evaluation of riprap design procedures.” Report 89-4128, U.S. Geological Survey.

Brayshaw, A. C., Frostick, L. E., and Reid, I. (1983). "The hydrodynamics of particle clusters and sediment entrapment in coarse alluvial channels." Sedimentology, 30(1), 137-143.

Church, M. and Hassan, M. A. (2002). "Mobility of bed material in harris creek.” Water Resources Research, 38(11), 19-1-19-12 1237.

Church, M., Hassan, M. A., and Wolcott, J. F. (1998). "Stabilizing self-organized structures in gravel-bed stream channels: Field and experimental observations." Water Resources Research, 34(11), 3169-3179.

Dermisis, D. and Papanicolau, T. (2014). “The effects of protruding rock boulders in regulating sediment intrusion within the hyporheic zone of mountain streams." Journal of Mountain Science, 11(6), 1466-1477.

Detert, M. and Weitbrecht, V. (2013). "User guide to gravelometric image analysis by basegrain." Advances in River Sediment Research.

Egiazaroff, I. V. (1965). “Calculation of nonuniform sediment concentrations.” ASCE, 91(4), 225246.

Ghilardi, T., Franca, M. J., and Schleiss, A. J. (2014a). "Bed load fluctuations in a steep channel." Water Resources Research, 50(8), 6557-6576.

Ghilardi, T., Franca, M. J., and Schleiss, A. J. (2014b). "Period and amplitude of bedload pulses in a macro-rough channel." Geomorphology, 221, 95 - 103.

Hassan, M. A. and Church, M. (2000). "Experiments on surface structure and partial sediment 
transport on a gravel bed." Water Resources Research, 36(7), 1885-1895.

Hassan, M. A. and Reid, I. (1990). “The influence of microform bed roughness elements on flow and sediment transport in gravel bed rivers." Earth Surface Processes and Landforms, 15(8), 739-750.

IOWA Department of Natural Resources (2006). How to Control Streambank Erosion.

Jafarnejad, M., Franca, M. J., Pfister, M., and Schleiss, A. J. (2019). “Effect of a second layer on the time to failure of compressed riprap as mountain riverbank protection." Journal of Hydraulic Research, 57(4), 573-578.

Juez, C., Marwan, M., and Franca, M. J. (2018). “The origin of fine sediment determines the observations of suspended sediment fluxes under unsteady flow conditions." Water Resources Research, 115, 5654-5669.

Julien, P. Y. (2002). River Mechanics. Cambridge University Press.

Mao, L. (2012). "The effect of hydrographs on bed load transport and bed sediment spatial arrangement." Journal of Geophysical Research: Earth Surface, 117(F3), 2156-2202 F03024.

Monsalve, A. and Yager, E. M. (2017). "Bed surface adjustments to spatially variable flow in low relative submergence regimes.” Water Resources Research, 53(11), 9350-9367.

Monsalve, A., Yager, E. M., and Schmeeckle, M. W. (2017). "Effects of bed forms and large protruding grains on near-bed flow hydraulics in low relative submergence conditions." Journal of Geophysical Research: Earth Surface, 122(10), 1845-1866.

Nitsche, M., Rickenmann, D., Turowski, J. M., Badoux, A., and Kirchner, J. W. (2011). "Evaluation of bedload transport predictions using flow resistance equations to account for macro-roughness in steep mountain streams." Water Resources Research, 47(8).

Odgaard, A. J. (2015). "River channel stabilization with submerged vanes." Advances in water resources engineering, Springer, 107-136.

Orrú, C., Blom, A., and Uijttewaal, W. S. J. (2016). “Armor breakup and reformation in a degradational laboratory experiment.” Earth Surface Dynamics, 4(2), 461-470.

Papanicolaou, A. N., Achilleas, G. T., Wyssmann, M. A., and Kramer, C. M. (2018). “Boulder array 
effects on bedload pulses and depositional patches." Journal of Geophysical Research, 123(11), 2925-295.

Parker, G. (1990). "Surface-based bedload transport relation for gravel rivers.” Journal of Hydraulic Research, 28(4), 417-436.

Parker, G., Klingeman, P., and McLean, D. (1983). "Bedload and size distribution in paved gravelbed streams." Journal of Hydraulic Engineering, 109(5), 793-794.

Plumb, B. (2017). "Impacts of hydromodification and sediment supply alterations on bedload transport and bed morphology in urbanizing gravel-bed rivers." Ph.D. thesis, University of Waterloo, Waterloo, Ontario, Canada.

Plumb, B., Annable, W., Juez, C., McKie, C. W., and Franca, M. (2019). “The impact of hydrograph variability and frequency on sediment transport dynamics in a gravel-bed flume." Earth Surface Processes and Landforms, In press, -.

Stähly, S., Friedrich, H., and Detert, M. (2017). "Size ratio of fluvial grains' intermediate axes assessed by image processing and square-hole sieving." Journal of Hydraulic Engineering, 143(6), 06017005.

Strom, K., Papanicolaou, A. N., Evangelopoulos, N., and Odeh, M. (2004). "Microforms in gravel bed rivers: Formation, disintegration, and effects on bedload transport." Journal of Hydraulic Engineering, 130(6), 554-567.

Sutton, H. (2008). "Shoreline erosion control failures and how to avoid them." report, Illinois Lake Management Association and Lake Rip Rap, Inc.

Tan, L. and Curran, J. C. (2012). "Comparison of turbulent flows over clusters of varying density." Journal of Hydraulic Engineering, 138(12), 1031-1044.

Tritico, H. M. and Hotchkiss, R. H. (2005). "Unobstructed and obstructed turbulent flow in gravel bed rivers." Journal of Hydraulic Engineering, 131(8), 635-645.

van Dijk, W. M., Teske, R., van de Lageweg, W. I., and Kleinhans, M. G. (2013). "Effects of vegetation distribution on experimental river channel dynamics." Water Resources Research, 49(11), 7558-7574. 
Resloping, rock toe and rip rap, Bank stabilization (2013).

Waters, K. A. and Curran, J. C. (2015). "Linking bed morphology changes of two sediment mixtures to sediment transport predictions in unsteady flows." Water Resources Research, 51(4), 2724-2741.

Wilcock, P. R. and Crowe, J. C. (2003). "Surface-based transport model for mixed-size sediment." Journal of Hydraulic Engineering, 129(2), 120-128.

Wilcock, P. R. and McArdell, B. W. (1997). "Partial transport of a sand/gravel sediment." Water Resources Research, 33(1), 235-245.

Wilcock, P. R. and Southard, J. B. (1988). "Experimental study of incipient motion in mixed-size sediment." Water Resources Research, 24(7), 1137-1151.

Williams, G. P. (1989). "Sediment concentration versus water discharge during single hydrologic events in rivers.” Journal of Hydrology, 111(1-4), 89-106.

Wong, M. and Parker, G. (2006). "Reanalysis and correction of bed-load relation of meyer-peter and muller using their own database." Journal of Hydraulic Engineering-asce - J HYDRAUL ENG-ASCE, 132.

Wu, W., Wang, S. S., and Jia, Y. (2000). “Nonuniform sediment transport in alluvial rivers.” Journal of Hydraulic Research, 38(6), 427-434.

Yager, E. M., Kirchner, J. W., and Dietrich, W. E. (2007). "Calculating bed load transport in steep boulder bed channels." Water Resources Research, 43(7), W07418 W07418.

Yager, E. M. and Schmeeckle, M. W. (2013). "The influence of vegetation on turbulence and bed load transport." Journal of Geophysical Research: Earth Surface, 118(3), 1585-1601.

Yager, E. M., Turowski, J. M., Rickenmann, D., and McArdell, B. W. (2012). "Sediment supply, grain protrusion, and bedload transport in mountain streams." Geophysical Research Letters, 39(10), W07418 L10402. 
1 Particle spacing for each test case . . . . . . . . . . . . . . 34 
TABLE 1. Median diameter of particle distribution $(D)$, distance between centers of particles $(\lambda)$, and number of particles per square $\operatorname{meter}\left(N / \mathrm{m}^{2}\right)$, and area occupied by the particles as a percentage of total area $\left(A_{i} / A_{t}\right)$ for each of the cases tested in this study. In addition, flow depth range (related to the base flow and to the peak flow, see Figure 2) is provided.

\begin{tabular}{ccccccc}
\hline Experiment Case & $\lambda / D$ & $D(\mathrm{~mm})$ & $\lambda(\mathrm{mm})$ & $N / \mathrm{m}^{2}$ & $A_{i} / A_{t}(\%)$ & Flow depth range $(\mathrm{m})$ \\
\hline Base Case & N/A & N/A & N/A & 0 & 0 & $0.0248-0.0518$ \\
Test Case 1 & 1.92 & 24.1 & 46 & 465 & $24.6 \%$ & $0.0322-0.0612$ \\
Test Case 2 & 2.63 & 24.4 & 64 & 244 & $13.2 \%$ & $0.0323-0.0619$ \\
Test Case 3 & 3.82 & 25.6 & 98 & 105 & $6.2 \%$ & $0.0332-0.0589$ \\
Test Case 4 & 5.17 & 25.0 & 129 & 60 & $3.4 \%$ & $0.0345-0.0599$ \\
Test Case 5 & 6.75 & 25.4 & 171 & 34 & $2.0 \%$ & $0.0369-0.0590$
\end{tabular}




\section{List of Figures}

1 Schematic of the experimental channel. . . . . . . . . . . . . 38

2 Flume experiment flow rates, sediment input rates and the sample collection schedule for each hydrograph. This figure is idealized and thus, between each varying flow and sediment input rate a time lag occurs. Numbers within the shaded boxes represent the bulk samples that were weighted, and the numbers above the shaded boxes represent the bulk samples that were consolidated prior to size analysis. . . . 39

3 Large immobile particles on the bed surface and superimposed sampling grid on bed surface photo (left). Processed images from Test Case 3 (right). Images A) and B) are heat maps before and after the hydrograph, respectively. The blue intensity represents coarse material spacing and black areas represent the large immobile particle locations. Image C) is the comparison of image A) and B), where green represents an increase in particle clustering, and red a decrease. Black patches in this image are the removed areas where large particles were located. . . . . . . . 40

4 Sediment transport ratio for sediment transported over the entire hydrograph in each test case. The horizontal dashed lines indicates a value where sediment into the system is equal to sediment leaving the system. Additionally the coarse material (gravel) and the fine material (sand) are plotted separately to depict STR of each of these fractions individually. A) represents sediment transported during the entire hydrograph, whereas B) looks at the transported sediment during the 1-minute peak discharge step only. . . . . . . . . . . . . . . . . . . 41

5 Change in the sediment size of transported material presented as a percent change in size fractions from the base case, $100 \cdot\left(D_{i}-D_{i, b a s e}\right) / D_{i, \text { base }}$ (i.e. if the $D_{50}$ is $1 \mathrm{~mm}$ for the base case, and $2 \mathrm{~mm}$ for the test case, this would be represented on the plot as 100\%). The horizontal dashed line represents no change from the base case. A) represents all sediment collected during the entire hydrograph, and B) shows only sediment collected during the 1-minute peak discharge step only . . 
6 Increase in bed material size fractions found after the hydrograph with decreasing spacing, represented as percent change from the results of the base case, $100 \cdot\left(D_{i}-\right.$ $\left.D_{i, \text { base }}\right) / D_{i, \text { base }}$. The horizontal dashed line represents no change from the base case value. . . . . . . . . . . . . . . . . . . . 4

7 The change in bed elevation (dark grey) at the end of the experiment with respect to the pre-hydrograph/initial situation $\left(\right.$ Elevation $_{\text {final }}-$ Elevation $\left._{\text {initial }}\right)$ and the final bed slope at the end of the experiment (light grey). . . . . . . . . . . . . . . 44

8 Results of the particle clustering analysis, displaying the mean ratio (circles), the increasing/decreasing area ratio (crosses), and the sum ratio (triangles). The horizontal dashed line represents values where the particle clustering is equivalent between the beginning and completion of each hydrograph. . . . . . . . . . . 45

9 Bedload phase plots for two representative cases, Test Case 3 (left) and Test Case 4 (right), depicted as the sediment transport ratio at various steps of the hydrograph. The base case is plotted against both test cases for scale and comparison. The horizontal dashed line represents equal sediment entering and exiting the system of the course of the hydrograph step. Filled symbols indicate steps on the rising limb of each hydrograph, hollow symbols identify falling limb observations. . . . . . . . 46

10 Hysteresis ratio versus large immobile particle spacing. The horizontal dashed line represents the conditions where an equivalent amount of sediment is transported on each limb. The base case has been plotted on the left for comparison to the test

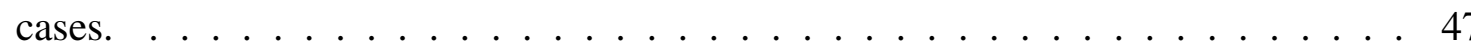

11 Dimensionless bedload rating curve for all cases. The modified form of the MeyerPeter and Muller bedload transport was plotted for comparison (solid line). . . . . . 48 
12 Fractional transport ratio for for all cases. Fractional transport ratio compares the representation of a material in the bedload compared to the same materials representation in the bed material mixture. Triangular symbols represent steps of the hydrograph on the rising limb, whereas circular symbols represent steps on the falling limb. . . . . . . . . . . . . . . . . . . . 49

13 Scaled fractional transport rates for for all cases. Triangular symbols represent steps of the hydrograph on the rising limb, whereas circular symbols represent steps on the falling limb. . . . . . . . . . . . . . . . 50 
FLOW CONTROL VALVE

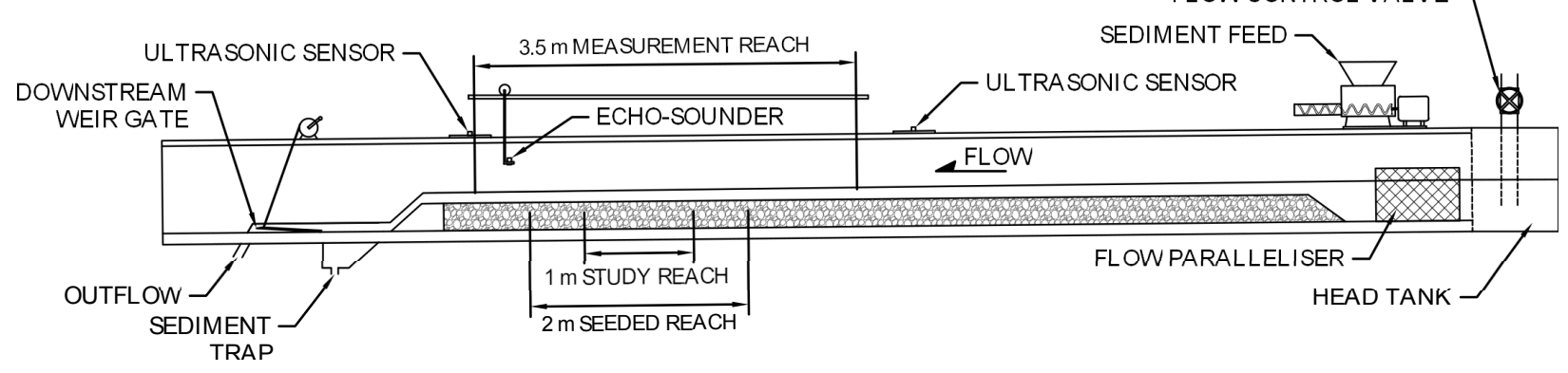

Fig. 1. Schematic of the experimental channel. 


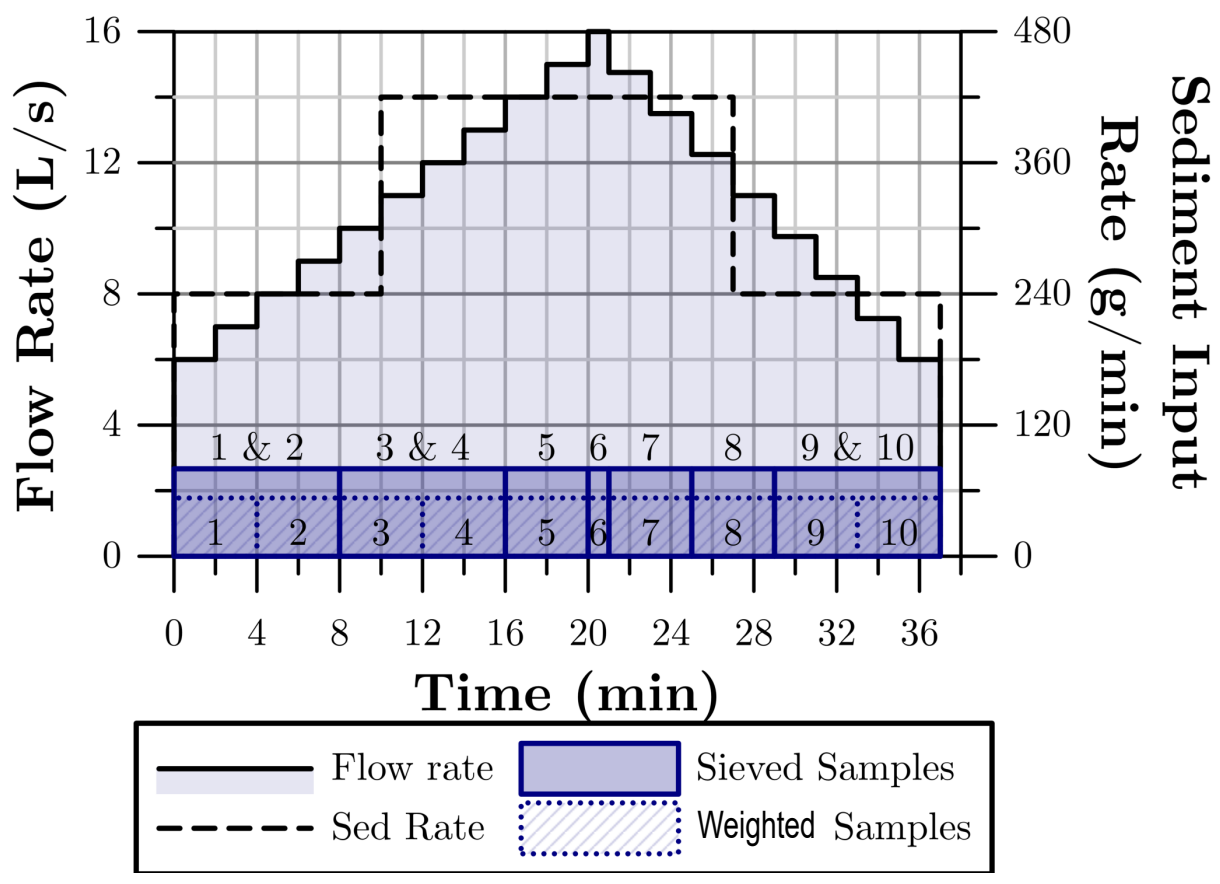

Fig. 2. Flume experiment flow rates, sediment input rates and the sample collection schedule for each hydrograph. This figure is idealized and thus, between each varying flow and sediment input rate a time lag occurs. Numbers within the shaded boxes represent the bulk samples that were weighted, and the numbers above the shaded boxes represent the bulk samples that were consolidated prior to size analysis. 


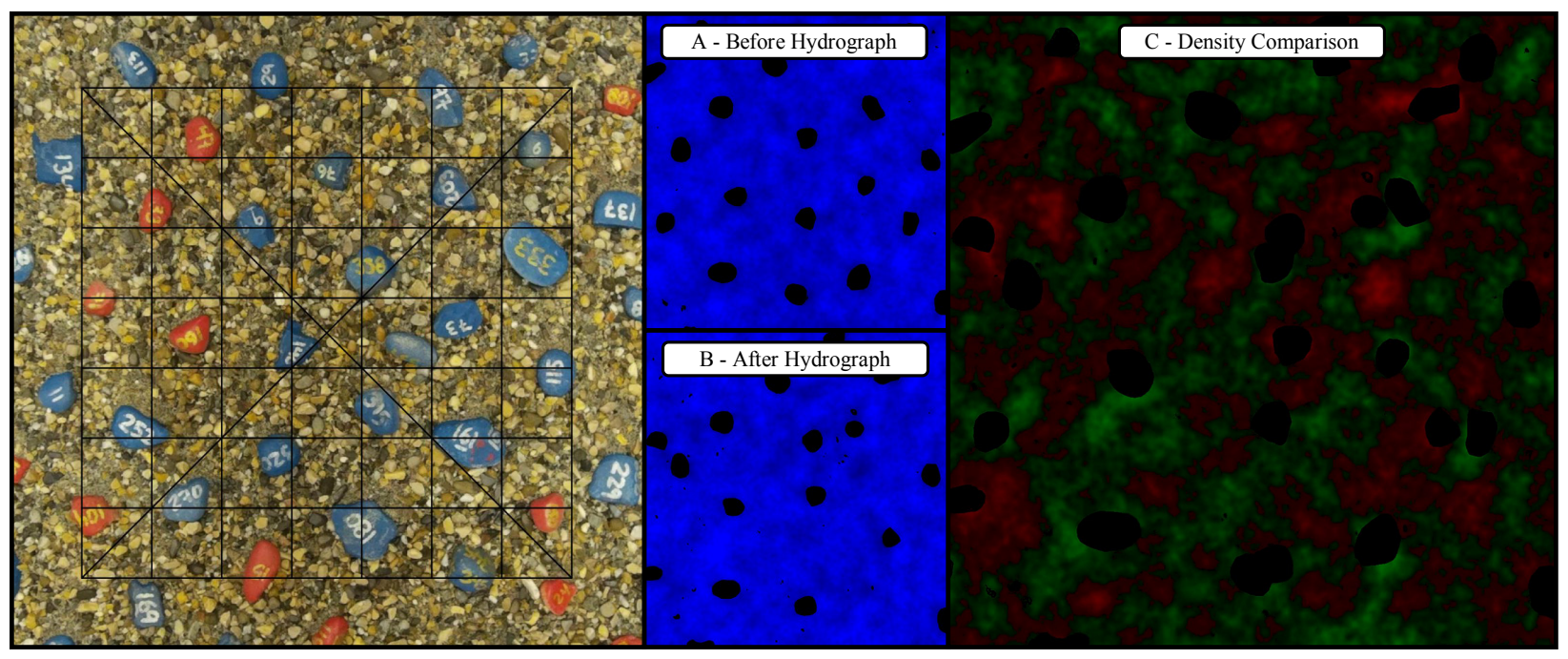

Fig. 3. Large immobile particles on the bed surface and superimposed sampling grid on bed surface photo (left). Processed images from Test Case 3 (right). Images A) and B) are heat maps before and after the hydrograph, respectively. The blue intensity represents coarse material spacing and black areas represent the large immobile particle locations. Image $C$ ) is the comparison of image A) and B), where green represents an increase in particle clustering, and red a decrease. Black patches in this image are the removed areas where large particles were located. 


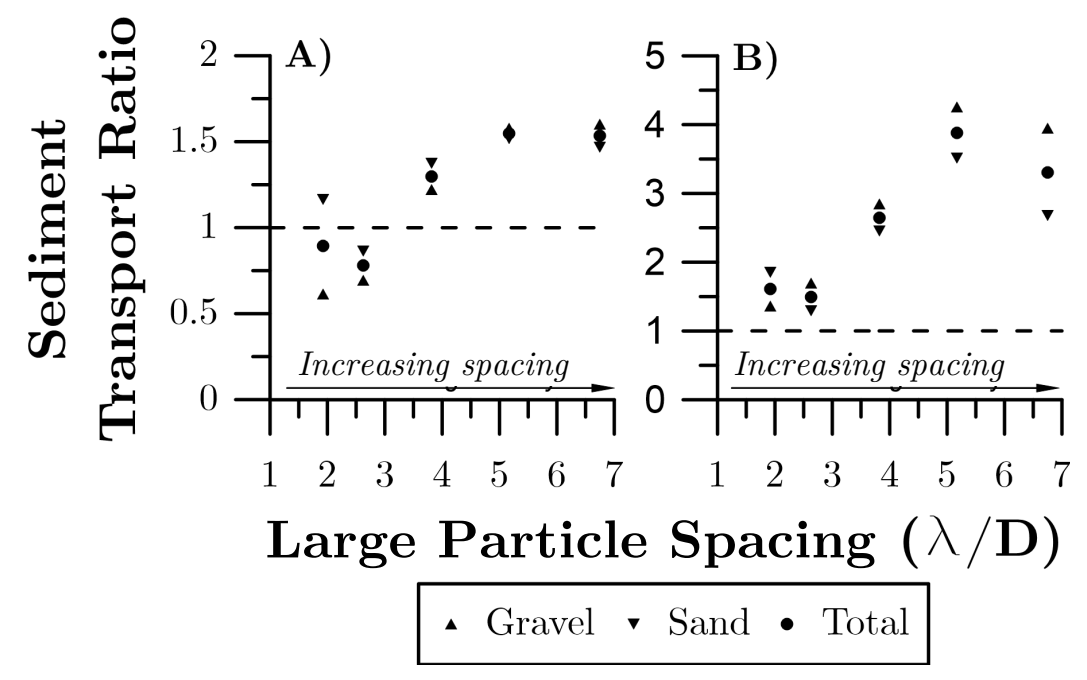

Fig. 4. Sediment transport ratio for sediment transported over the entire hydrograph in each test case. The horizontal dashed lines indicates a value where sediment into the system is equal to sediment leaving the system. Additionally the coarse material (gravel) and the fine material (sand) are plotted separately to depict STR of each of these fractions individually. A) represents sediment transported during the entire hydrograph, whereas B) looks at the transported sediment during the 1-minute peak discharge step only. 


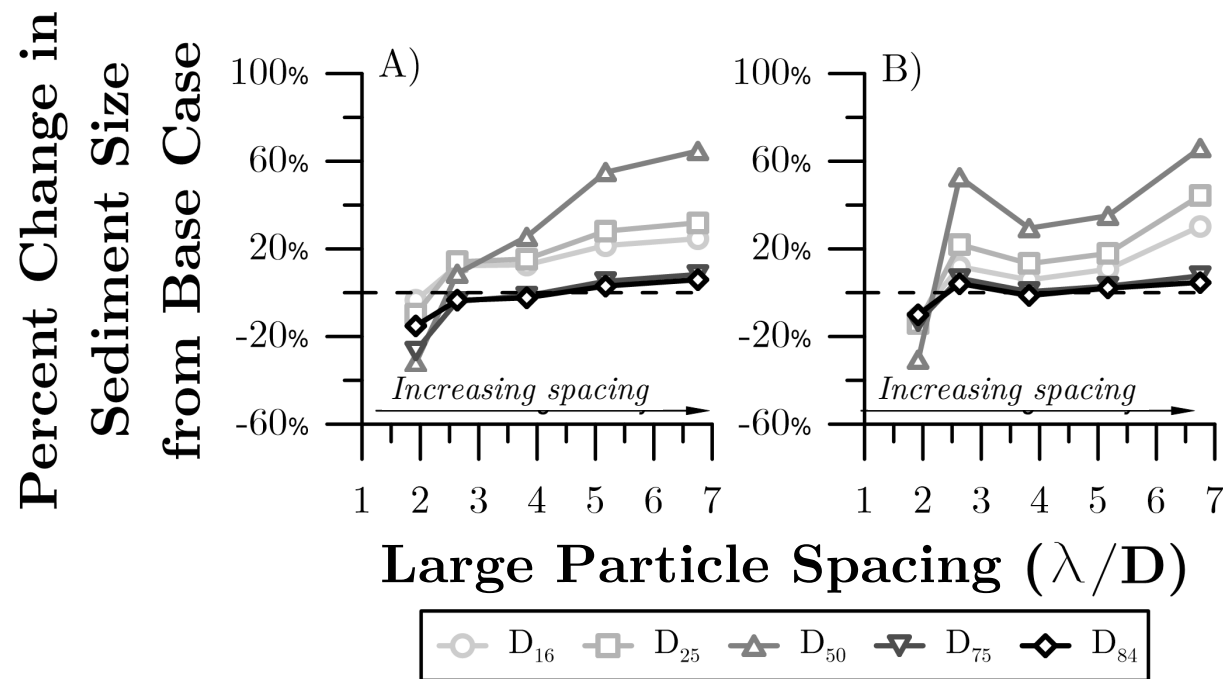

Fig. 5. Change in the sediment size of transported material presented as a percent change in size fractions from the base case, $100 \cdot\left(D_{i}-D_{i, \text { base }}\right) / D_{i, \text { base }}$ (i.e. if the $D_{50}$ is $1 \mathrm{~mm}$ for the base case, and $2 \mathrm{~mm}$ for the test case, this would be represented on the plot as 100\%). The horizontal dashed line represents no change from the base case. A) represents all sediment collected during the entire hydrograph, and B) shows only sediment collected during the 1-minute peak discharge step only 


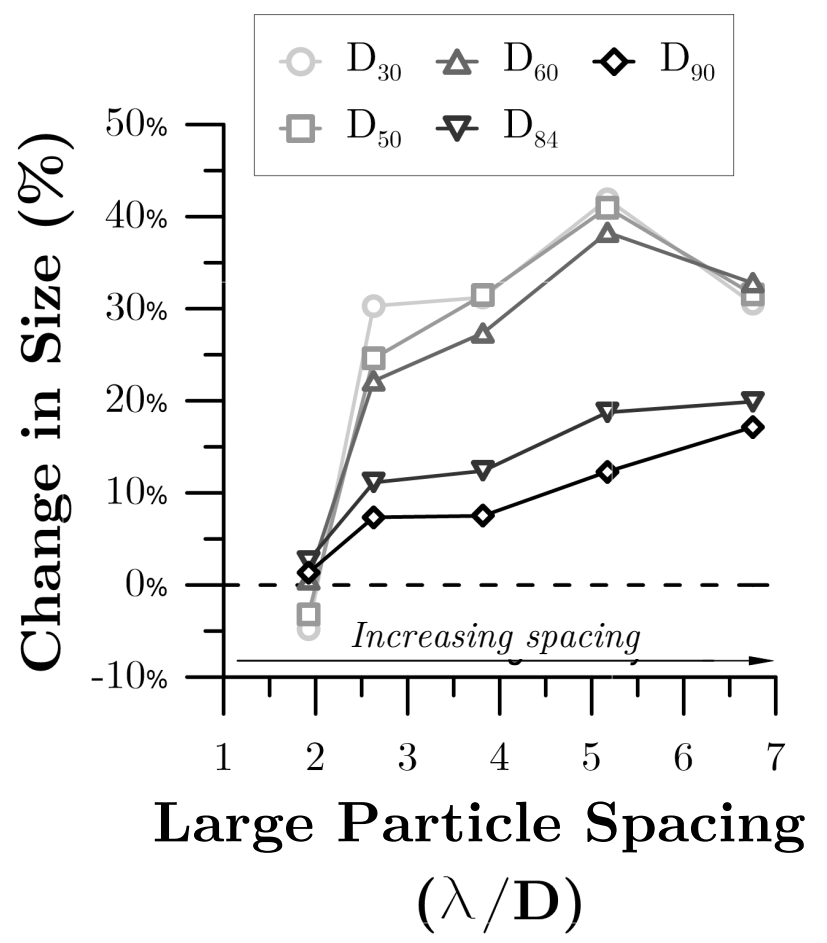

Fig. 6. Increase in bed material size fractions found after the hydrograph with decreasing spacing, represented as percent change from the results of the base case, $100 \cdot\left(D_{i}-D_{i, \text { base }}\right) / D_{i, \text { base. }}$. The horizontal dashed line represents no change from the base case value. 


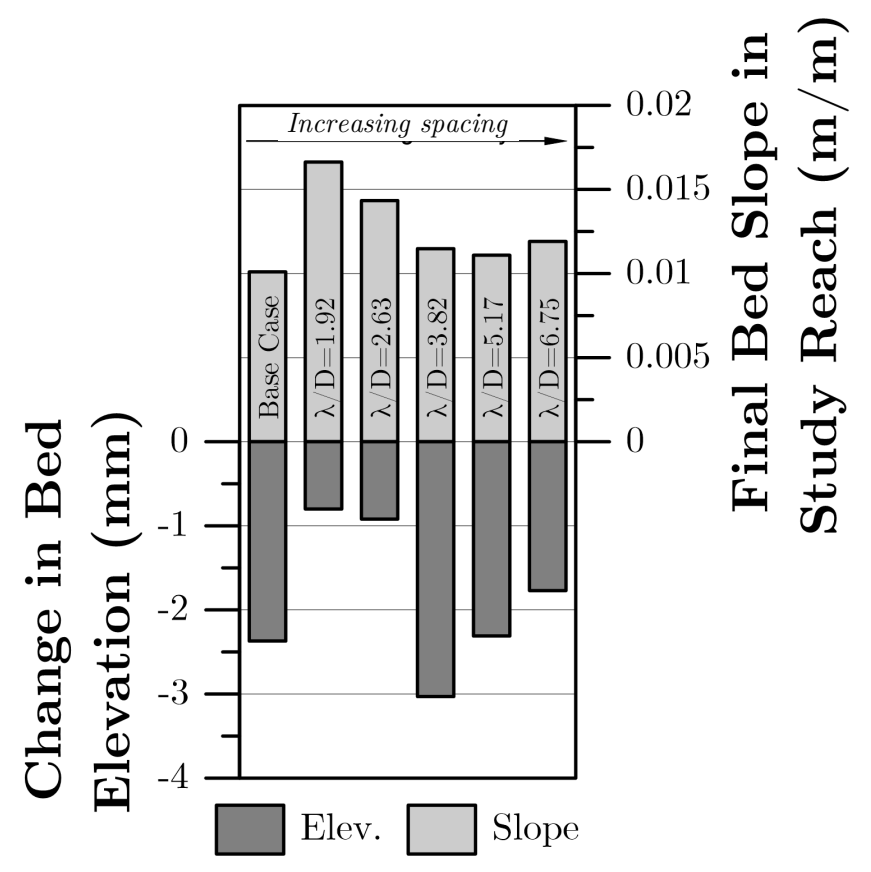

Fig. 7. The change in bed elevation (dark grey) at the end of the experiment with respect to the pre-hydrograph/initial situation (Elevation final $_{-}-$Elevation $_{\text {initial }}$ ) and the final bed slope at the end of the experiment (light grey). 


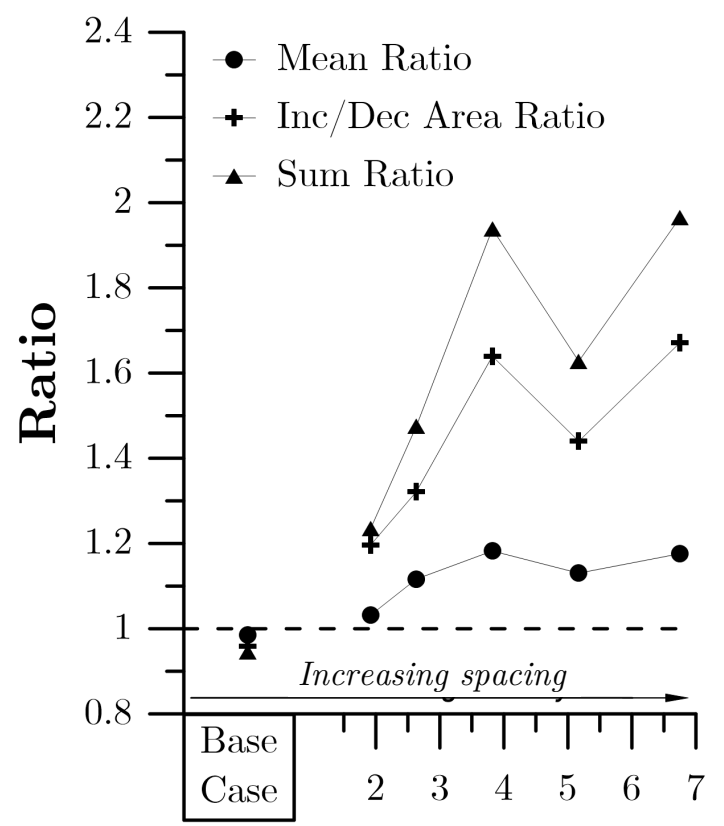

Large Particle Spacing

$(\lambda / \mathbf{D})$

Fig. 8. Results of the particle clustering analysis, displaying the mean ratio (circles), the increasing/decreasing area ratio (crosses), and the sum ratio (triangles). The horizontal dashed line represents values where the particle clustering is equivalent between the beginning and completion of each hydrograph. 

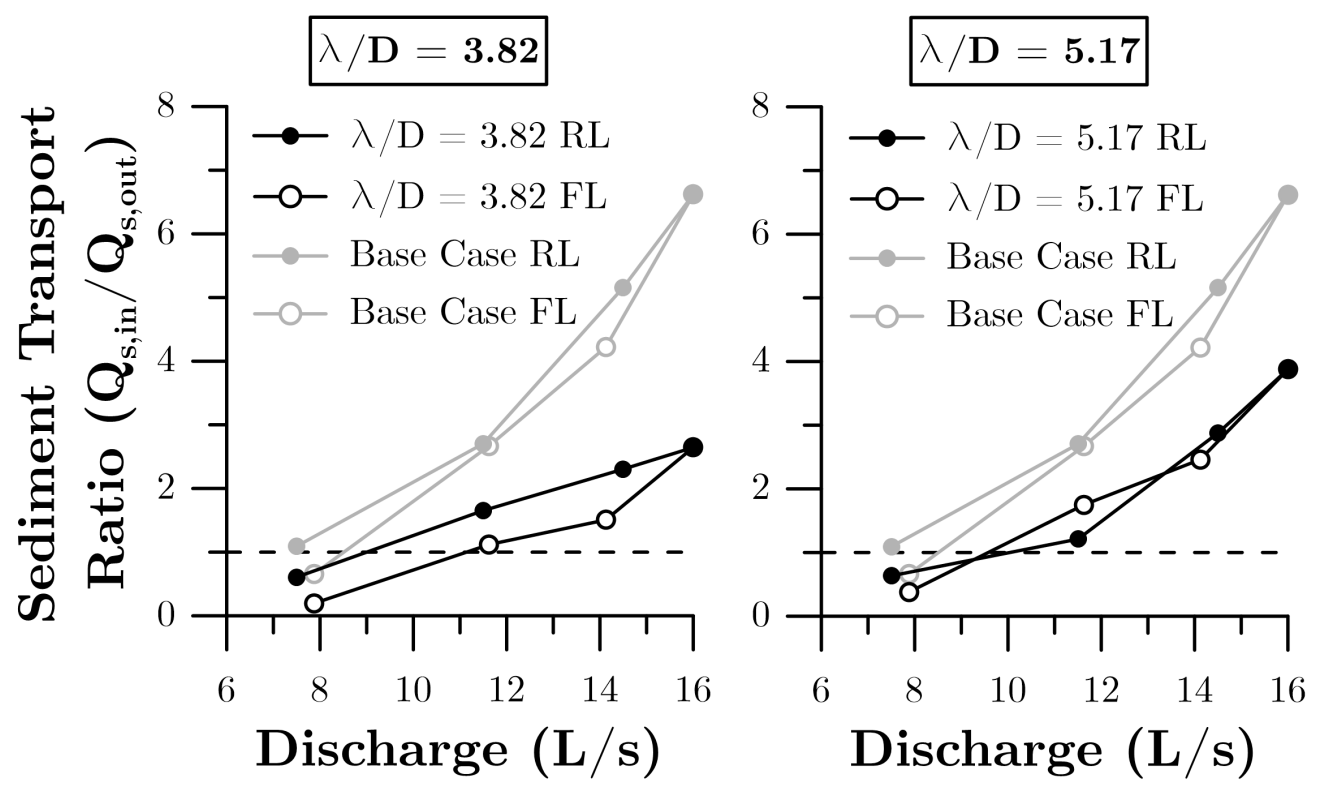

Fig. 9. Bedload phase plots for two representative cases, Test Case 3 (left) and Test Case 4 (right), depicted as the sediment transport ratio at various steps of the hydrograph. The base case is plotted against both test cases for scale and comparison. The horizontal dashed line represents equal sediment entering and exiting the system of the course of the hydrograph step. Filled symbols indicate steps on the rising limb of each hydrograph, hollow symbols identify falling limb observations. 


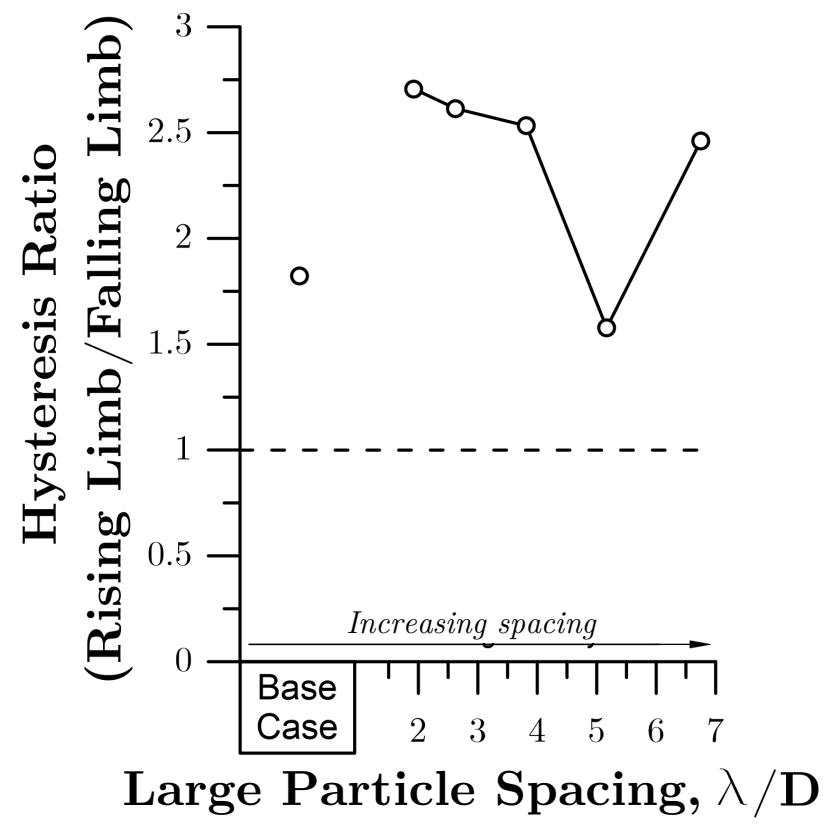

Fig. 10. Hysteresis ratio versus large immobile particle spacing. The horizontal dashed line represents the conditions where an equivalent amount of sediment is transported on each limb. The base case has been plotted on the left for comparison to the test cases. 


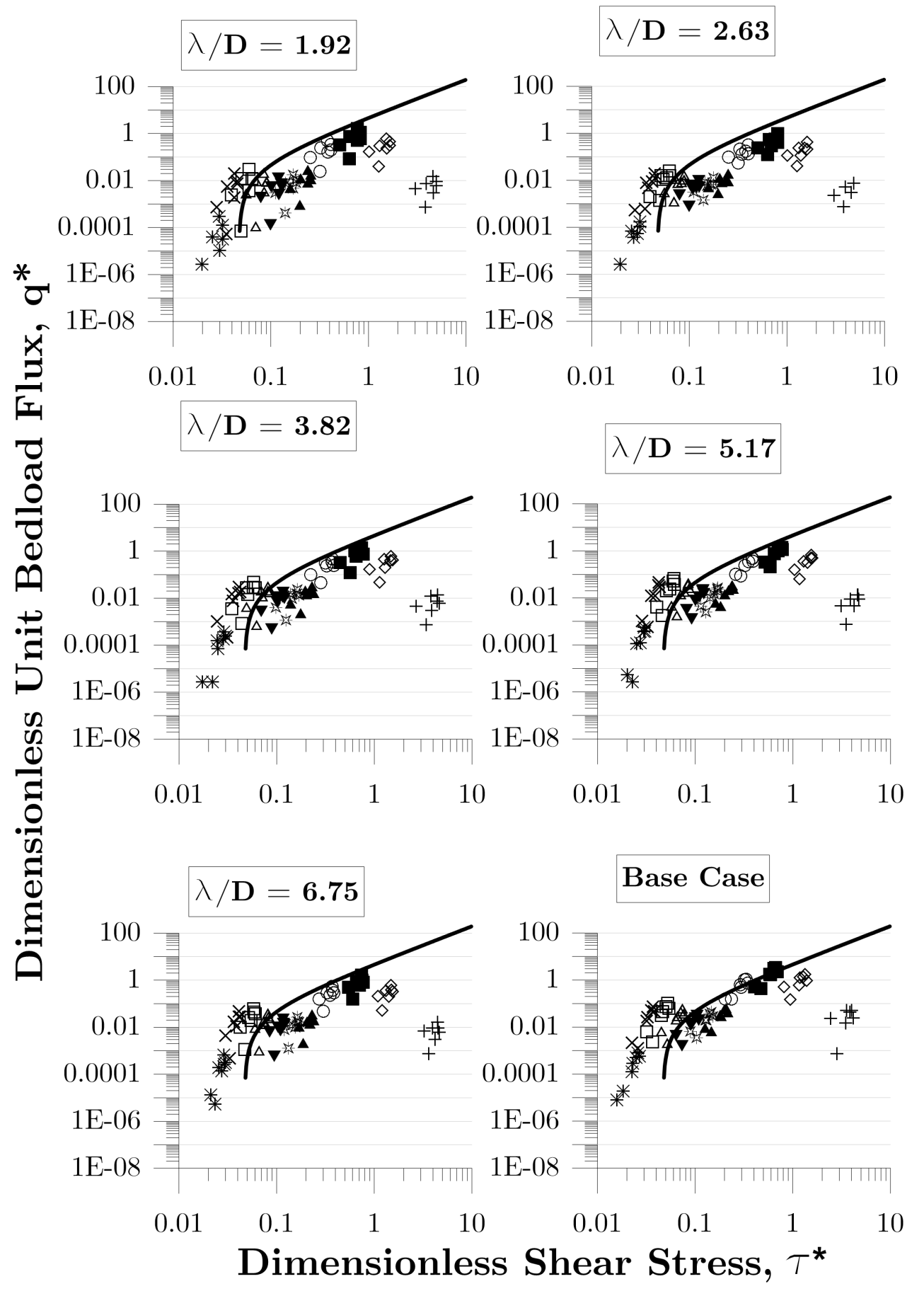

\begin{tabular}{|c|c|c|c|c|c|c|c|c|c|}
\hline \multicolumn{10}{|c|}{ Particle Size (mm) } \\
\hline - & $>11.3$ & $\square$ & $4-5.6$ & 海 & $1.41-2$ & $\mathbf{\square}$ & $0.25-0.5$ & + & $<0.125$ \\
\hline * & $8-11.3$ & $\Delta$ & $2.8-4$ & $\Delta$ & $1-1.41$ & $\diamond$ & $0.125-0.25$ & - & Meyer-Peter and Müller \\
\hline$\times$ & $5.6-8$ & $\boldsymbol{\nabla}$ & $2-2.8$ & 0 & $0.5-1$ & & & & \\
\hline
\end{tabular}

Fig. 11. Dimensionless bedload rating curve for all cases. The modified form of the Meyer-Peter and Muller bedload transport was plotted for comparison (solid line). 


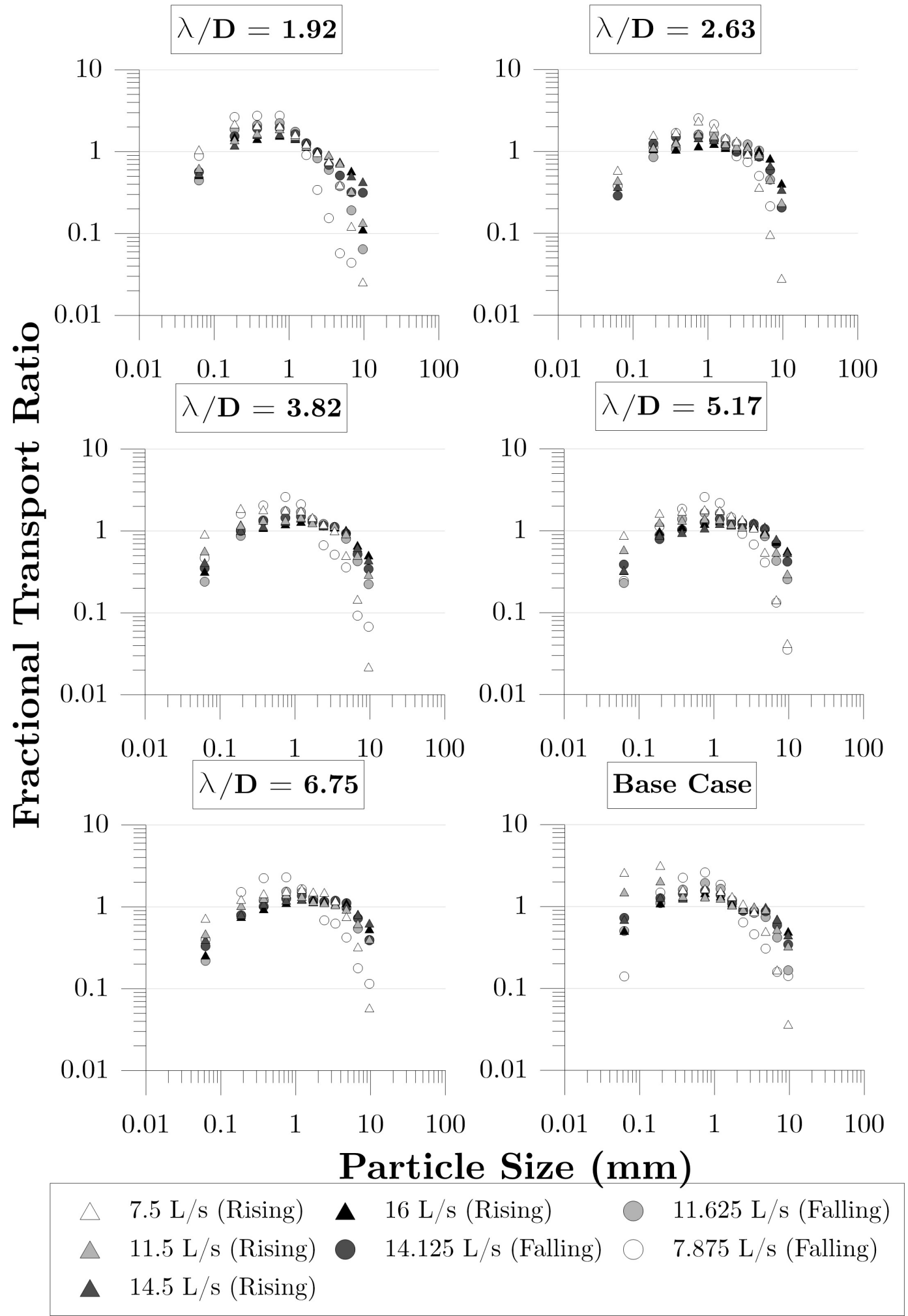

Fig. 12. Fractional transport ratio for for all cases. Fractional transport ratio compares the representation of a material in the bedload compared to the same materials representation in the bed material mixture. Triangular symbols represent steps of the hydrograph on the rising limb, whereas circular symbols represent steps on the falling limb. 


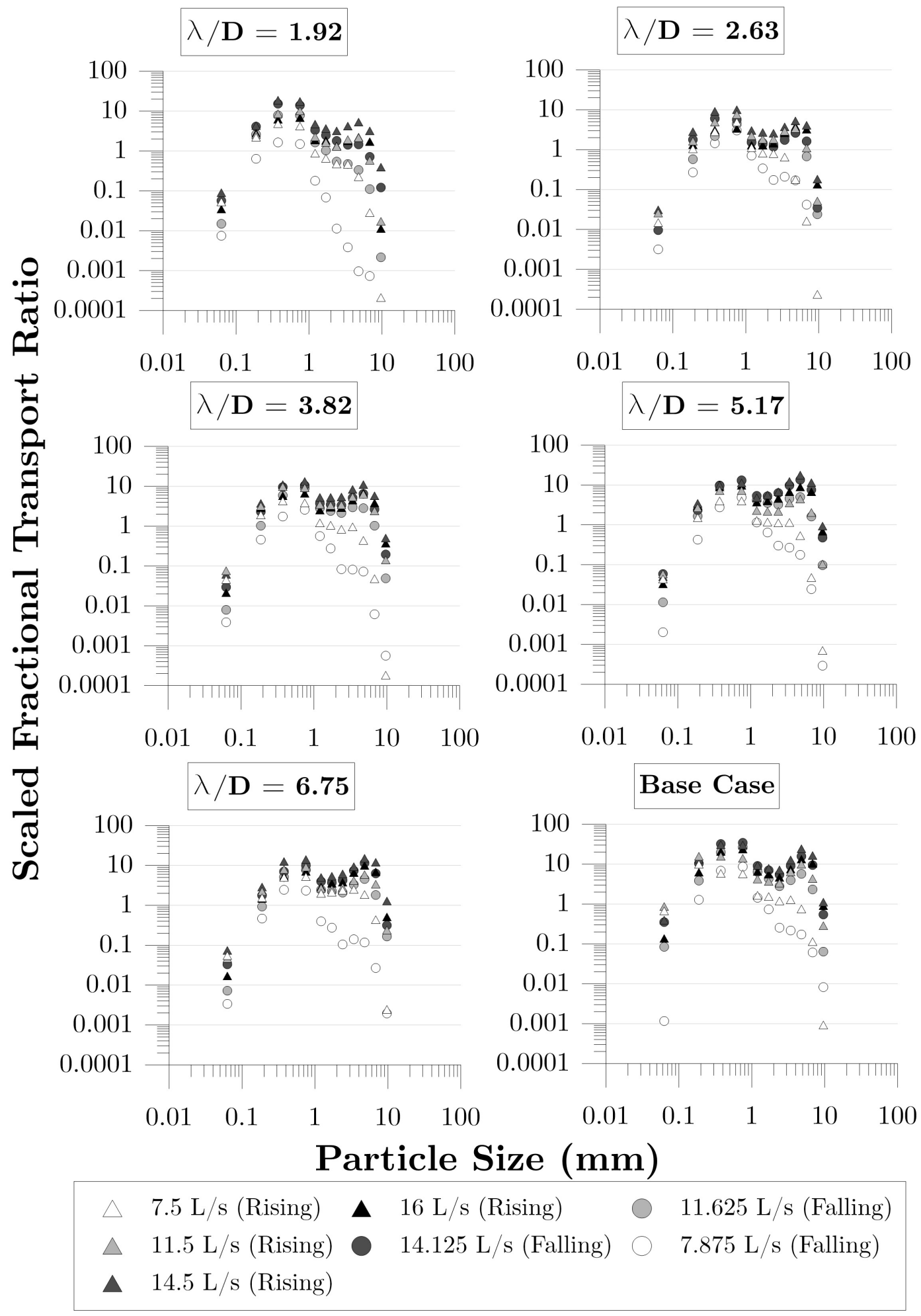

Fig. 13. Scaled fractional transport rates for for all cases. Triangular symbols represent steps of the hydrograph on the rising limb, whereas circular symbols represent steps on the falling limb. 